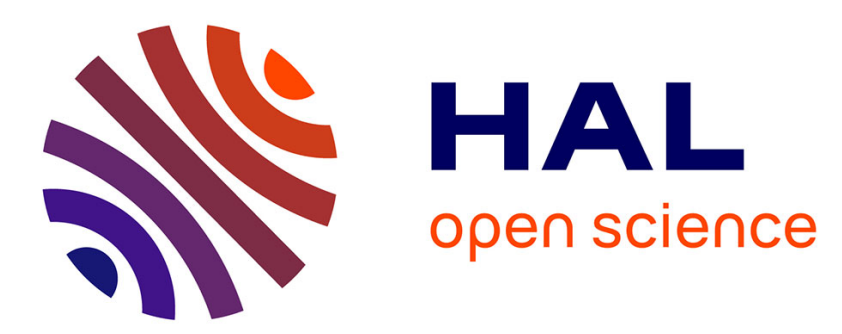

\title{
In situ characterization of Si-based anodes by coupling synchrotron X-ray tomography and diffraction
}

\author{
V. Vanpeene, A. King, E. Maire, L. Roue
}

\section{To cite this version:}

V. Vanpeene, A. King, E. Maire, L. Roue. In situ characterization of Si-based anodes by coupling synchrotron X-ray tomography and diffraction. Nano Energy, 2019, 56, pp.799-812. 10.1016/j.nanoen.2018.11.079 . hal-01969058

\section{HAL Id: hal-01969058 \\ https://hal.science/hal-01969058}

Submitted on 20 Jan 2022

HAL is a multi-disciplinary open access archive for the deposit and dissemination of scientific research documents, whether they are published or not. The documents may come from teaching and research institutions in France or abroad, or from public or private research centers.
L'archive ouverte pluridisciplinaire HAL, est destinée au dépôt et à la diffusion de documents scientifiques de niveau recherche, publiés ou non, émanant des établissements d'enseignement et de recherche français ou étrangers, des laboratoires publics ou privés. 
In situ characterization of Si-based anodes by coupling synchrotron X-ray tomography and diffraction

V. Vanpeene ${ }^{\mathrm{a}, \mathrm{b}}$, A. King ${ }^{\mathrm{c}}$, E. Maire ${ }^{\mathrm{b},{ }^{*}}$ and L.Roué ${ }^{\mathrm{a},{ }^{*}}$

a Institut National de la Recherche Scientifique (INRS) - Centre Énergie, Matériaux, Télécommunications (EMT), J3X 1S2 Varennes (QC) Canada

${ }^{b}$ MATEIS - CNRS UMR 5510 INSA Lyon, F-69621 Villeurbanne, France

${ }^{c}$ Synchrotron Soleil, Psiché beamline, F-91190 Gif-sur-Yvette, France

* Corresponding authors:

E-mail: eric.maire@insa-lyon.fr (E. Maire), lionel.roue@emt.inrs.ca (L. Roué) 


\begin{abstract}
In the present work, combined synchrotron X-ray tomography/diffraction analyses are performed along the $1^{\text {st }}$ and $10^{\text {th }}$ cycles of a Si-based anode made with nanocrystalline/amorphous $\mathrm{Si}$ particles synthetized by ball-milling. We are using a porous $\mathrm{C}$ paper as a current collector instead of a conventional $\mathrm{Cu}$ foil and graphene nanoplatelets as a conductive additive instead of usual carbon black. It is shown that this specific formulation has a major impact on the structural changes of the electrode occurring upon cycling by $(i)$ preventing its macroscopic cracking and related electrical disconnections, (ii) limiting its volume expansion and improving its reversibility, indicative of limited permanent damage in the electrode architecture, (iii) preventing the formation of $\mathrm{c}-\mathrm{Li}_{15} \mathrm{Si}_{4}$ which is known to be detrimental for the electrode cyclability. However, the capacity fade with cycling remains significant. It can result from the accumulation of SEI products with cycling, progressively obstructing the porous network of the electrode, as supported by a significant decrease of the electrode porosity from 48 to $21 \%$ between the $1^{\text {st }}$ and $10^{\text {th }}$ cycle. The displacement and/or micro-cracking of the $\mathrm{Si}$ particles can also induce some electrical disconnections and irreversibility of the lithiation reaction. However, this degradation process occurring at the particle scale cannot be clearly identified from the present in-situ XRCT measurements due to spatial resolution limitation.
\end{abstract}

Keywords: Li-ion batteries; silicon anode; in-situ X-ray tomography; in-situ X-ray diffraction. 


\section{Introduction}

Lithium-ion batteries (LIB) are presently the best performing technology for powering electrical vehicles (EVs). However, the energy density, charge rate and cost of the LIB need to be improved to compete with internal-combustion engine vehicles. Indeed, although the cost of the LIB pack for EVs has been reduced from $\$ 1000$ to $\$ 268$ per $\mathrm{kWh}$ with a simultaneous increase in their energy density from 55 to $295 \mathrm{Wh} \mathrm{L}^{-1}$ between 2008 and 2015, the current LIB pack cost is still $>2$ times higher than the United States Advanced Battery Consortium (USABC) target $\left(\$ 125 \mathrm{kWh}^{-1}\right)$ [1]. A promising and moderate risk pathway to meet this target is to use a high-capacity silicon anode paired with a high-capacity/voltage cathode (e.g. Li and Mn-rich (LMR) layered oxide) instead of the common graphite anode / lithium-nickelmanganese-cobalt-oxide (NMC) cathode system [2].

Silicon is a very attractive LIB anode material due to its specific capacity 10 times higher than graphite (3579 $\mathrm{mAh} \mathrm{g}^{-1}$ for $\mathrm{Li}_{15} \mathrm{Si}_{4}$ versus $372 \mathrm{mAh} \mathrm{g}^{-1}$ for $\mathrm{LiC}_{6}$ ). However, the use of Sibased anodes for LIBs remains a challenge. This is related to the huge volume change of $\mathrm{Si}$ upon its lithiation (up to $280 \%$ for $\mathrm{Li}_{15} \mathrm{Si}_{4}$ versus $\sim 10 \%$ for $\mathrm{LiC}_{6}$ ), which causes deterioration of the architecture of the electrode (rupture of the conductive network) and destabilizes the solid electrolyte interphase (SEI). Despite significant progress in recent years to solve these issues $[3,4]$, the implementation of $\mathrm{Si}$ in commercial LIBs is presently limited to low Si contents (a few $w t \%$ in graphite anodes) and for electronic devices that do not require a long cycle life.

To optimize the electrochemical performance of Si-based anodes, it is highly relevant to characterize in detail their morphological evolution upon cycling, and how this depends on their composition and manufacture. For this purpose, X-Ray computed tomography (XRCT) is certainly one of the most powerful analytical tools [5]. This technique permits non-destructive 3D imaging of objects with complex and porous morphologies such as LIB electrodes. Using appropriate image processing, segmentation and analysis procedures, quantitative parameters 
can be extracted such as the volume fraction, the size distribution, the connectivity and the geometrical tortuosity of the constitutive phases of the LIB electrodes. The differentiation (segmentation) of the individual phases (e.g. active material, carbon additive, binder, electrolyte) within LIB electrodes can be however difficult due to their small size or when they have low and/or similar X-ray attenuation coefficients. To accentuate their differentiation, phase contrast can be used, which requires a synchrotron X-ray source. A spatial resolution of a few tens of nm can be reached with a synchrotron X-ray source compared to a few $\mu \mathrm{m}$ with a conventional laboratory X-ray source. Moreover, the acquisition time of synchrotron XRCT is typically 2-3 orders of magnitude faster than with a laboratory source, enabling imaging of a dynamically evolving system.

Recently, in situ XRCT has been successfully used for studying Si-based anodes [6-13]. These studies have given qualitative and quantitative information (with a voxel size ranging from $9.3 \mu \mathrm{m}$ [6] to $0.16 \mu \mathrm{m}$ [12]) on various morphological changes occurring upon cycling such as the electrode delamination [6], Si particle volume change and cracking [7], formation of gas channels [8], Si particle disconnection [9], electrode volume change and lithiation extent of the Si particles [10], fracture propagation in $\mathrm{Si}$ particles [11], variation of the size, connectivity and volume fraction of the solid, electrolyte and gas phases [12]. XRCT analyses can also be combined with other characterization techniques like X-ray diffraction (XRD) in order to have complementary information about the lithiation mechanism of the electrode [13]. Note that all these XRCT studies on Si-based anodes have been focused on the first cycle.

In the present work, combined synchrotron XRCT / XRD analyses are performed along the $1^{\text {st }}$ and $10^{\text {th }}$ cycles of a Si-based anode made with nanocrystalline/amorphous Si particles and using a porous $\mathrm{C}$ paper as a current collector instead of a conventional $\mathrm{Cu}$ foil and with graphene nanoplatelets as a conductive additive instead of usual carbon black. It is shown that 
this specific electrode formulation has a major impact on the structural changes of the electrode occurring upon cycling.

\section{Experimental}

\subsection{Materials}

Ball-milled Si powder was used as active material. Si powder $(99.999 \%, 20$ mesh, Materion) was milled under argon atmosphere for $20 \mathrm{~h}$ using a SPEX 8000 mixer with a ballto-powder mass ratio of 5:1. As a result of the repeated particle fracturing and cold-welding events occurring during the ball-milling process, the as-milled $\mathrm{Si}$ powder consists of micrometric agglomerates made of sub-micrometric particles more or less welded together (Fig 1a). The ball-milling also results in a partial amorphization of the Si powder as confirmed from Raman spectroscopy analysis (Fig. 1b). The Raman spectrum of the Si powder before milling displays only a narrow peak centered at $520 \mathrm{~cm}^{-1}$ characteristic of crystalline silicon whereas after $20 \mathrm{~h}$ of milling two peaks are discernable, one related to crystalline $\mathrm{Si}\left(\mathrm{c}-\mathrm{Si}\right.$ ) at $520 \mathrm{~cm}^{-1}$ and a second broader peak centered at about $470 \mathrm{~cm}^{-1}$ characteristic of amorphous $\mathrm{Si}$ (a-Si) [14]. From the integrated intensity of these two peaks determined after appropriate deconvolution of the spectrum and according to the calculation procedure detailed in ref. [14], the fraction of amorphous Si in the milled powder was estimated at $63 \%$. From the XRD patterns of the asreceived and milled Si powders (see supplementary Fig. S1) and using the Scherrer-Wilson formula [15], the crystallite size and the lattice strain of the c-Si phase were estimated at $15 \mathrm{~nm}$ and $0.11 \%$ for the milled Si powder versus $37 \mathrm{~nm}$ and $0.015 \%$ for the as-received Si powder. The amorphization of Si originates from the high density of defects such as deformation twins, stacking faults and lattice dislocations generated by the high-energy ball milling process [16].

Graphene nanoplatelets $(\mathrm{GnP})(\mathrm{M}$ grade from XGSciences, average diameter $=15 \mu \mathrm{m}$, average thickness $=6-8 \mathrm{~nm}$, surface area $=120-150 \mathrm{~m}^{2} \mathrm{~g}^{-1}$ according to the supplier's data) was 
used as conductive additive (Fig. 1c). For comparison, some electrodes were also prepared with carbon black (CB) (Super P grade from Imerys Graphite \& Carbon, particle size $\sim 40 \mathrm{~nm}, \mathrm{~S}_{\mathrm{BET}}$ $=62 \mathrm{~m}^{2} \mathrm{~g}^{-1}$ according to the supplier's data) as conductive additive. Carboxymethyl cellulose $(\mathrm{CMC})\left(\mathrm{DS}=0.7, \mathrm{Mw}=90000 \mathrm{~g} \mathrm{~mol}^{-1}\right.$, Sigma-Aldrich) was used as binder. A carbon paper (AvCarb EP40 from Fuel Cell Store) was used as 3D current collector (Fig. 1d). It consists of non-woven carbon fibers $(\sim 10 \mu \mathrm{m}$ diam.) bound by a binder filled with micrometric carbon particles. Its mean thickness is $163 \pm 2 \mu \mathrm{m}$, its areal weight is $3.37 \pm 0.05 \mathrm{mg} \mathrm{cm}^{-2}$ and its mean porosity is $\sim 82 \%$ with a median pore diameter of $36 \mu \mathrm{m}$ [12]. Citric acid and KOH salts (SigmaAldrich) were used to prepare a $\mathrm{pH} 3$ buffer solution $(0.17 \mathrm{M}$ citric acid $+0.07 \mathrm{M} \mathrm{KOH})$ as slurry medium.
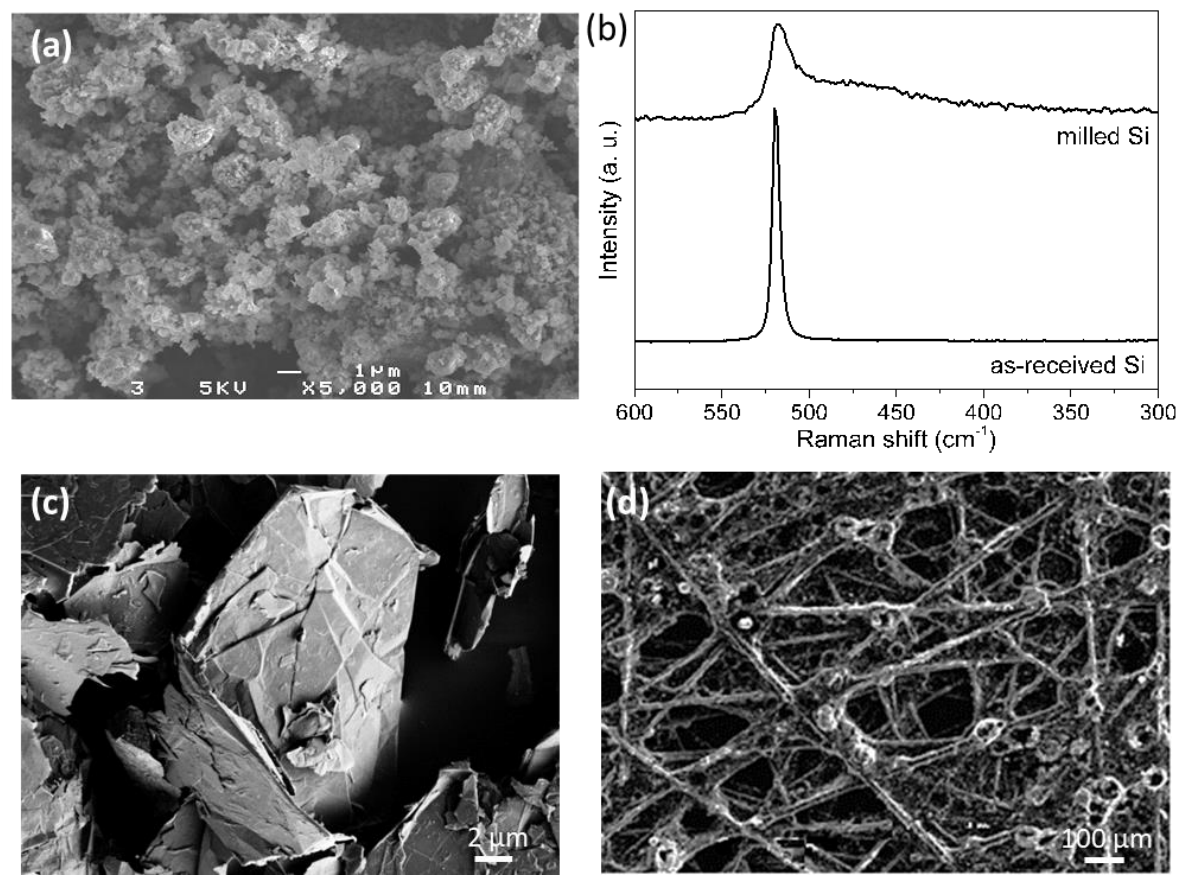

Figure 1 (a) SEM image of the milled Si powder. (b) Raman spectra of as-received and milled Si powder. (c) SEM image of the graphene nanoplatelets. (d) SEM image of the $\mathrm{C}$ paper.

\subsection{Electrode preparation and cell assembly}


A slurry was prepared by mixing $200 \mathrm{mg}$ of $80 \%^{\mathrm{wt}} \mathrm{Si}, 8 \%{ }^{\mathrm{wt}} \mathrm{CMC}$ and $12 \%^{\mathrm{wt}} \mathrm{GnP}$ in $0.5 \mathrm{ml} \mathrm{pH} 3$ buffer solution. The use of a buffered $\mathrm{pH} 3$ solution instead of neutral water as slurry medium promotes covalent bonding between $\mathrm{OH}$ groups present on the Si particles and $\mathrm{COOH}$ groups of $\mathrm{CMC}$, which improves the mechanical strength and cycling performance of the electrode $[\mathbf{1 7 , 1 8}] .150 \mu \mathrm{L}$ of isopropanol was added to the slurry, which favors a homogeneous impregnation of the hydrophobic $\mathrm{C}$ paper by the aqueous slurry. This is highlighted in supplementary Fig. S2, which compares the volumetric distribution profiles of the Si particles along the $x, y$ and $z$ axes of the electrode prepared with or without isopropanol in the slurry.

The slurry mixing was performed at $500 \mathrm{rpm}$ for $1 \mathrm{~h}$ using a Fritsch Pulverisette 7 mixer with 3 silicon nitride balls (9.5 $\mathrm{mm}$ diameter). During this mixing step, there is a deagglomeration of the as-milled Si powder, resulting in a significant decrease of the Si particle size with a median diameter of $0.8 \mu \mathrm{m}$ versus $6 \mu \mathrm{m}$ in the as-milled state (see their respective particle size distribution curve in supplementary Fig. S3). In order to have a larger fraction of Si particles discernible by in situ XRCT (i.e. having a diameter larger than the present XRCT resolution of $1.3 \mu \mathrm{m}$ ), a less intensive slurry mixing procedure consisting in a magnetic stirring at $500 \mathrm{rpm}$ for $1 \mathrm{~h}$ was used for the preparation of the electrode analysed by in situ XRCT/XRD. The resulting Si powder has a median diameter of $2.4 \mu \mathrm{m}$ and about $70 \mathrm{vol} . \%$ of the particles have a diameter $>1.3 \mu \mathrm{m}$ (see curve $c$ in supplementary Fig. S3).

The composite electrode was obtained by successive soaking (typically 2-3 times) of the carbon paper ( 3 or $10 \mathrm{~mm}$ diam. disc) in the slurry. Slurry excess was removed from the carbon paper surface by using an absorbent paper followed by a short drying period of $\sim 2 \mathrm{~min}$ in air at each step of impregnation. The electrode was dried at room temperature for $12 \mathrm{~h}$ and then at $100^{\circ} \mathrm{C}$ under vacuum for $2 \mathrm{~h}$. The $\mathrm{Si}$ areal mass loading was $2-2.6 \mathrm{mg} \mathrm{cm}^{-2}$. For a loading of $2.6 \mathrm{mg} \mathrm{Si} \mathrm{cm} \mathrm{cm}^{-2}$, its weight composition was $47.4 \% \mathrm{C}$ paper, $38.5 \% \mathrm{Si}, 5.8 \% \mathrm{GnP}, 3.8 \% \mathrm{CMC}$, 
$4.0 \%$ citric acid $(\mathrm{CA})$ and $0.5 \% \mathrm{KOH}$ (the two latter are the residual salts from the $\mathrm{pH} 3$ buffer solution).

The cycling performance of the $\mathrm{Si} / \mathrm{C}$ paper electrode was evaluated using a conventional two-electrode Swagelok ${ }^{\circledR}$ cell made of stainless steel, in which the electrodes have a diameter of $10 \mathrm{~mm}$. For the in situ XRCT/XRD experiments, a smaller two-electrode Swagelok ${ }^{\circledR}$ cell with an electrode diameter of $3 \mathrm{~mm}$ was designed. A schematic representation of the cell is shown in supplementary Fig. S4. The cell was made of perfluoroalkoxy alkane (PFA) polymer with a wall thickness reduced to $2.5 \mathrm{~mm}$ near the electrode to ensure a lower X-ray attenuation and better image quality. In order to facilitate a good contact between the cell components, the cell was slightly compressed with a spring installed on the counter electrode side. A borosilicate glass-fiber (Whatman GF/D) was used as a separator and was soaked with an electrolytic solution of 1 M LiPF6 in ethylene carbonate (EC) and dimethyl carbonate (DMC) (1:1) with 10 wt. \% fluoroethylene carbonate (FEC). A lithium foil was used as the counter and reference electrode.

The electrodes were cycled in galvanostatic mode at full capacity between 0.005 and 1 $\mathrm{V}$ vs. $\mathrm{Li} / \mathrm{Li}^{+}$at a current density of $400 \mathrm{~mA} \mathrm{~g}^{-1}$ of $\mathrm{Si}(\mathrm{C} / 9)$ both in discharge (lithiation) and charge using an OrigaFlex OGF500 potentiostat/galvanostat for the in-situ XRCT/XRD experiments or an Arbin BT2000 cycler for the conventional cycling tests. All electrode capacities are given per gram of electrode (i.e. including the mass of the $\mathrm{C}$ paper current collector).

\subsection{SEM characterization}

Ion beam cross sectioning of the pristine electrode was performed using an Ilion ${ }^{+}$II Gatan apparatus and then characterized by scanning electron microscopy (SEM) using a SEM FEG ZEISS Ultra 55 microscope. 


\subsection{In situ synchrotron XRCT/XRD measurements}

In situ synchrotron XRCT/XRD measurements were performed on the Psiché beamline at the Soleil Synchrotron (Gif-sur-Yvette, France). The experimental setup is schematized in supplementary Fig. S4. XRCT and XRD analyses were successively carried out at regular intervals (typically every hour) during the $1^{\text {st }}$ and $10^{\text {th }}$ cycles. During these acquisition periods ( $\sim 1$ min for XRCT and $\sim 2$ min for XRD) plus $\sim 1$ min for switching from the tomography to the diffraction configuration of the beamline (moving the detectors and changing the beam focusing), the cell was let to the open circuit potential.

For the XRCT measurements, the synchrotron beam spectrum was restricted to $25 \pm 1$ keV using an x-ray mirror and Ag filters (see supplementary Fig. S5) [19]. A set of 1500 2D projections along a $180^{\circ}$ cell rotation with $45 \mathrm{~ms}$ of exposure per projection was acquired for each XRCT scan, corresponding to a scan duration of $\sim 1 \mathrm{~min} .3 \mathrm{D}$ tomographic volumes of 1333 $\times 1333 \times 208 \mu \mathrm{m}^{3}$ with an isotropic voxel size of $0.65 \mu \mathrm{m}$ (corresponding to a true spatial resolution of around $1.3 \mu \mathrm{m}$ ) were reconstructed in 32 bit floating-point representation from 2D projections using the PyHST2 software [20]. An analyzed volume of $943 \times 943 \times 208 \mu \mathrm{m}^{3}$ was extracted from the total volume. In the reconstructed volumes, the grayscale value represents the attenuation coefficient, so more attenuating (usually denser) regions are brighter. Image processing and analysis were performed with the Fiji software [21]. Image greyscale alignment was performed by taking the grey level of the separator as a reference. The image segmentation steps are presented in supplementary information (see Fig. S6 and related comments) and more details on the image processing can be found in our previous work [12].

For the XRD measurements, the tomography detector was moved out of the beam and the XRD detector was positioned at an angular position of $9.5^{\circ}$ and $1 \mathrm{~m}$ away from the sample. The incident beam was defined using slits to give a FWHM of $50 \mu \mathrm{m}$. The entire thickness of 
the electrode was exposed to the beam. The Ag filters were removed, to leave a broad band polychromatic beam. A germanium energy dispersive detector was used to acquire energy spectra. A pair of slits between the sample and the detector define the diffraction angle, and collimate the signal to a defined gauge volume located in the sample. The energy spectrum was centered around $30 \mathrm{keV}$ in the $15-60 \mathrm{keV}$ range (see supplementary Fig. S5). The signal was integrated over 2 minutes during a $360^{\circ}$ rotation of the electrochemical cell. The background signal measured without the electrochemical cell was fitted and then removed by subtraction from the XRD patterns as shown in supplementary Fig. S7. The XRD patterns, recorded as a function of energy at a fixed angle of $9.5^{\circ}$, were converted in d-spacing.

\section{Results and discussion}

\subsection{SEM observation of the pristine electrode}

Fig. 2 presents cross-sectional SEM images in backscattered-electron (BSE) mode of the pristine electrode before cell assembly. At low magnification (Fig. 2a), the fibers $(\sim 10 \mu \mathrm{m}$ diam.) of the C paper current collector are discernible, between which the Si-based composite seems to be well dispersed. Pores of various sizes (from several $\mu \mathrm{m}$ to $<1 \mu \mathrm{m}$ ) can also be seen. At higher magnification focused on a Si-rich zone (Fig. 2b), Si particles with irregular shape and different sizes (from $\sim 5 \mu \mathrm{m}$ to $\sim 0.1 \mu \mathrm{m}$ in diam.) and the GnP conductive additive consisting of stacks of graphene sheets $(\sim 5-15 \mu \mathrm{m}$ in length and $\sim 0.1-1 \mu \mathrm{m}$ in thickness $)$ are well discernible. The latter form a 3D conductive network between clusters of Si particles. CMC binder aggregates are not visible, suggesting that it is finely dispersed in the electrode. 


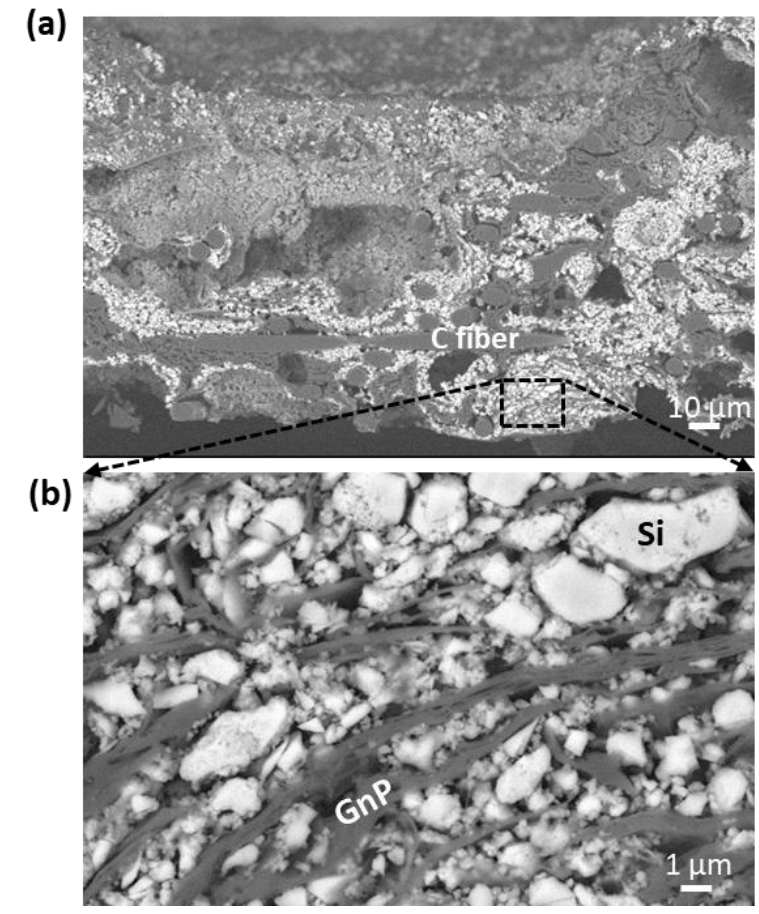

Figure 2 Cross-sectional SEM images (in BSE mode) at low (a) and high magnifications (b) of the pristine electrode before cell assembly.

\subsection{Electrochemical performance}

Fig. 3a-d compare the cycling performance of Si/C paper electrodes $\left(2 \mathrm{mg} \mathrm{Si} \mathrm{cm}^{-2}\right)$ prepared with GnP (blue curves) and $\mathrm{CB}$ (black curves) as conductive additive. A much better capacity retention is observed with the $\mathrm{GnP}$ additive with a discharge capacity measured at the $50^{\text {th }}$ cycle of $800 \mathrm{mAh} \mathrm{g}^{-1}$ of electrode $\left(4.3 \mathrm{mAh} \mathrm{cm}^{-2}\right)$ compared to $330 \mathrm{mAh} \mathrm{g}^{-1}\left(1.7 \mathrm{mAh} \mathrm{cm}^{-}\right.$ ${ }^{2}$ ) with $\mathrm{CB}$ additive (Fig. 3c). An improvement of the coulombic efficiency (CE) is also observed with an initial CE of $85 \%$, reaching $99.2 \%$ at the $10^{\text {th }}$ cycle and stabilizes at $99.5 \%$ from the $25^{\text {th }}$ cycle for the GnP-based electrode whereas for the CB-based electrode, its initial CE is $81 \%$ and needs about 40 cycles to reach a nearly stable value of $99.5 \%$ (Fig. 3d). As shown in a previous study on $\mathrm{Si}$ based electrodes prepared with a conventional $\mathrm{Cu}$ foil current collector and using different conductive additives ( $\mathrm{CB}, \mathrm{GnP}$ and carbon fibers), the better cycling stability obtained with $\mathrm{GnP}$ additive can be explained by its $2 \mathrm{D}$ morphology and 
flexibility, forming a conductive network that is better able to withstand the high volume variations of Si particles. By acting as a lubricant, $\mathrm{GnP}$ is also likely to promote a more homogeneous deformation of the electrode during its expansion/contraction. The flaky morphology of the GnP additive, offering large contact surface areas, may also favor numerous interactions through the binder molecules with the silicon particles that increases the cohesion strength of the electrode. As a result, the mechanical degradation of the electrode and associated electrical disconnection of the Si particles are minimized with GnP additive [22]. This is also in agreement with the present data showing a significant decrease of the relative irreversible capacity associated with the disconnection $\left(\mathrm{RIC}_{\text {discon. }}\right)$ defined as [22]:

$$
R I C_{\text {discon. }}=\frac{C_{C n}-C_{C n+1}}{C_{C n+1}}
$$

where $C_{C n}$ and $C_{C n+1}$ are the charge capacities at cycle $n$ and $n+1$, respectively. This calculation, as detailed in ref. [22], is based on the assumption that the electrical disconnections mostly occur during the deflation (delithiation) of the $\mathrm{SiLi}_{\mathrm{x}}$ particles inducing their irreversible displacement as well as the formation of cracks and delaminated zones in the electrode [12,23]. As shown in Fig. 3d, these disconnections are much lower with the $\mathrm{GnP}$ additive with a cumulated $\mathrm{RIC}_{\mathrm{discon}}$ value at the $50^{\text {th }}$ cycle of 0.3 versus 1.2 with the $\mathrm{CB}$ additive. Note that both these $\mathrm{RIC}_{\mathrm{dis}}$ values are about 2 times lower than those measured with Si-based electrodes of similar composition and Si loading $\left(2 \mathrm{mg} \mathrm{Si} \mathrm{cm}^{-2}\right)$ but prepared with a conventional $\mathrm{Cu}$ foil current collector [22], meaning that the present 3D and flexible C paper current collector also helps to maintain the electrical connections during cycling. 
(a)

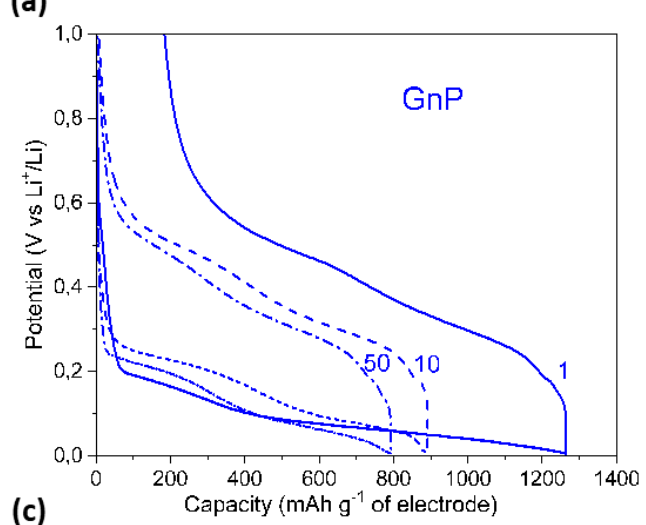

(c)

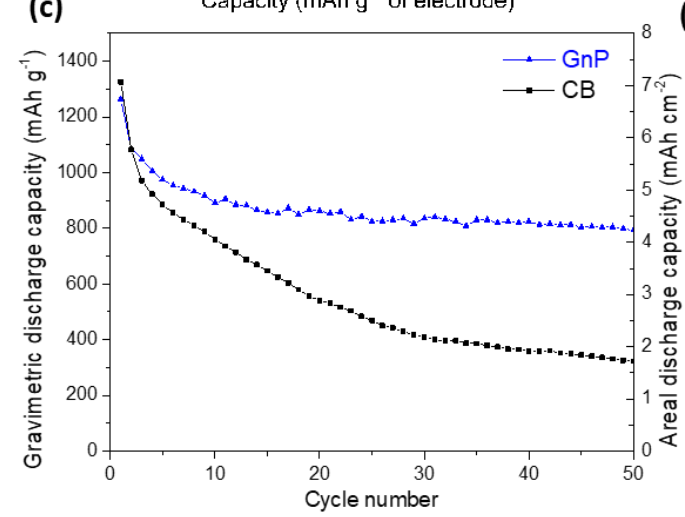

(b)

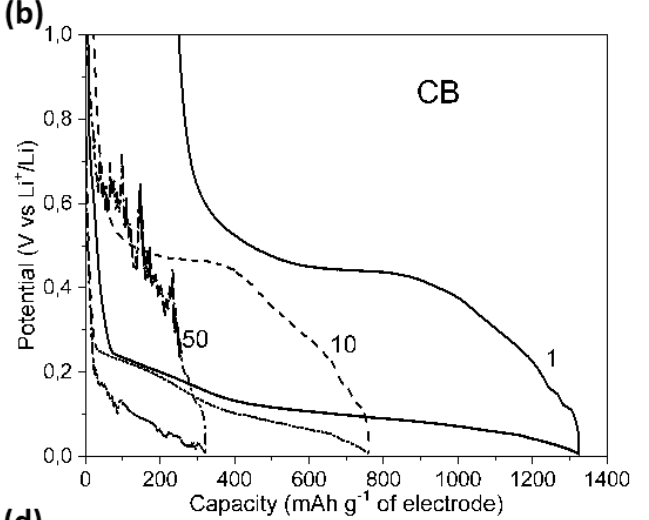

(d)

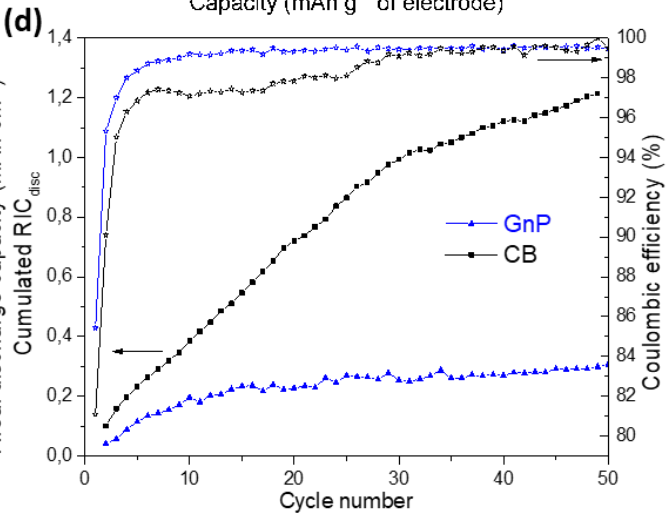

Figure 3 Cycling performance of $\mathrm{Si} / \mathrm{C}$ paper electrodes $\left(2 \mathrm{mg} \mathrm{Si} \mathrm{cm}^{-2}\right)$ prepared with $\mathrm{GnP}$ (blue curves) and CB (black curves) as conductive additive: $(a, b)$ discharge-charge curves at the $1^{\text {st }}, 10^{\text {th }}$ and $50^{\text {th }}$ cycles and evolution with cycling of the (c) gravimetric and areal discharge capacities, (d) coulombic efficiency and cumulated relative irreversible capacity loss due to disconnection ( $\left.\mathrm{RIC}_{\text {discon. }}\right)$.

\subsection{In situ XRCT analyses}

In order to characterize the morphological changes occurring during the cycling of a $\mathrm{Si} / \mathrm{C}$ paper electrode with GnP conductive additive, in situ XRCT analyses were performed during the $1^{\text {st }}$ and $10^{\text {th }}$ cycles. The Si areal mass loading of this electrode was $2.6 \mathrm{mg} \mathrm{cm}^{-2}$.

After appropriate segmentation of the XRCT images as described in supplementary Fig. S6, four distinctive phases can be identified, namely $(i)$ the $\mathrm{C}$-rich solid phase (i.e. the $\mathrm{C}$ paper $+\mathrm{GnP}+\mathrm{CMC}+\mathrm{CA})$. This phase also includes Si particles having a diameter lower than 1.3 
$\mu \mathrm{m}$, which cannot be segmented due to their size lower than the present XRCT spatial resolution; (ii) the Si phase (i.e. Si particles or clusters with a diameter $>1.3 \mu \mathrm{m}$ ); (iii) the electrolyte phase (i.e. pores filled with the electrolyte) and (iv) the gas phase (i.e. electrolytefree pores). Pores with a diameter $<1.3 \mu \mathrm{m}$ cannot be accurately characterized here.

Fig. 4 shows 3D views and distribution profiles along the $x, y$ and $z$ axes of these four segmented phases for the pristine electrode. Their spatial distribution appears rather homogeneous along the three axes of the electrode. Note that the pristine electrode is compressed in the cell since its thickness is $\sim 100 \mu \mathrm{m}$ compared to $\sim 160 \mu \mathrm{m}$ before cell assembly. The mean volume fraction of the segmented Si phase in the electrode is estimated at $8.2 \%$, which is lower than the value of $10.8 \%$ calculated from the electrode volume after cell assembly, the Si loading $\left(2.6 \mathrm{mg} \mathrm{cm}^{-2}\right)$ and the true density of $\mathrm{Si}\left(2.33 \mathrm{~g} \mathrm{~cm}^{-3}\right)$. This tends to confirm that a fraction of the Si particles are included in the segmented C-rich solid phase due to their small size. The median diameter $\left(D_{50}\right)$ of the detected Si particles is $6.5 \mu \mathrm{m}$. The porosity of the electrode is estimated at $48.3 \%$, which includes the electrolyte-filled pores $\left(13.3 \%, \mathrm{D}_{50}\right.$ $=7.3 \mu \mathrm{m})$ and the electrolyte-free pores $\left(35.0 \%, \mathrm{D}_{50}=27.2 \mu \mathrm{m}\right)$. The high volume fraction of electrolyte-free pores indicates that the impregnation of the electrode by the electrolyte is unfortunately incomplete. On the other hand, the volume fraction of electrolyte-filled pores may be underestimated due to resolution limitation, which does not permit the segmentation of the electrolyte phase located in the submicrometric interstices, e.g. between the Si particles or between the Si particles and the GnP flakes. 
(a) C-rich solid phase
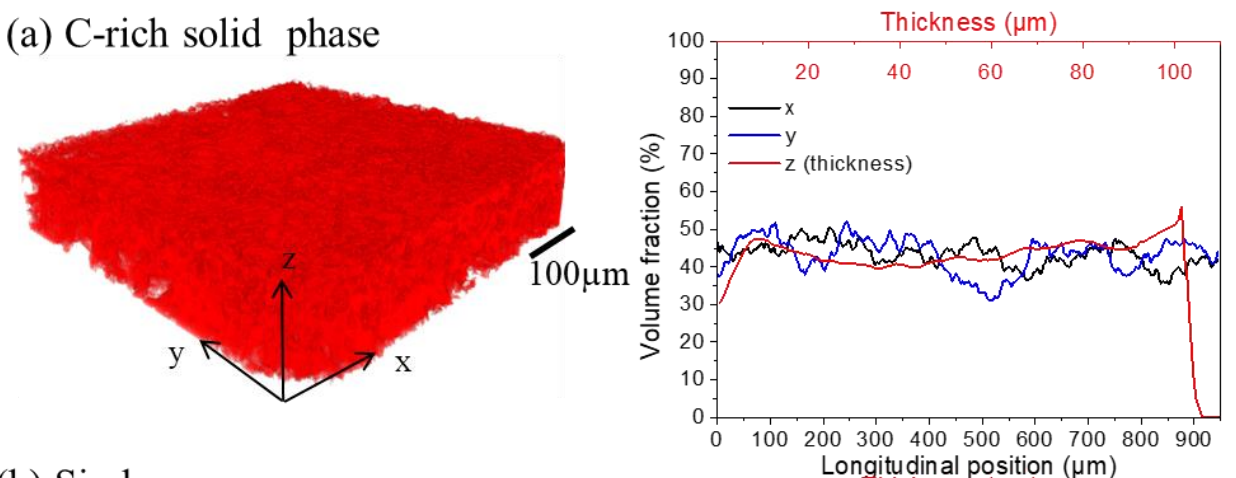

(b) Si phase
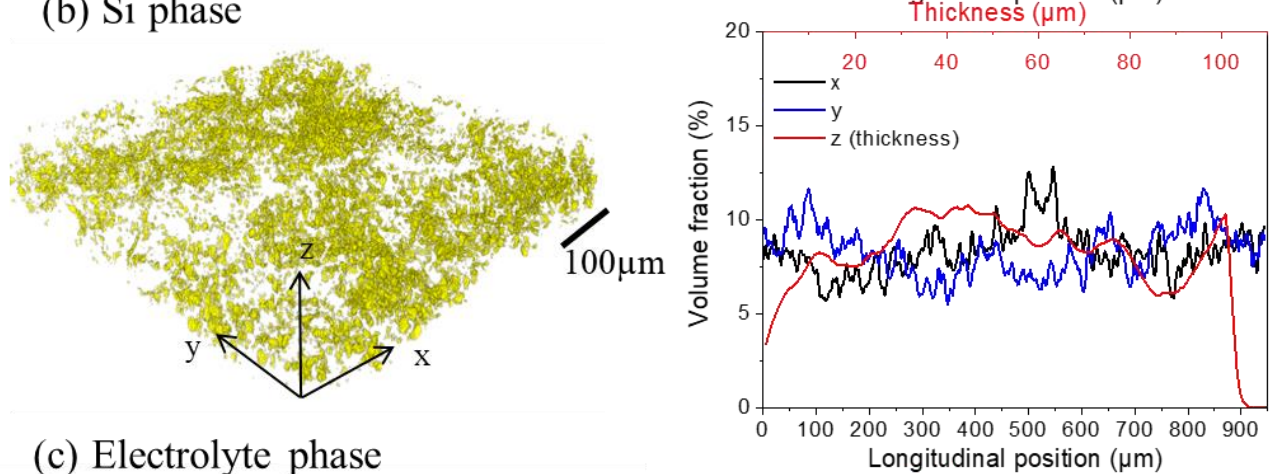

(c) Electrolyte phase
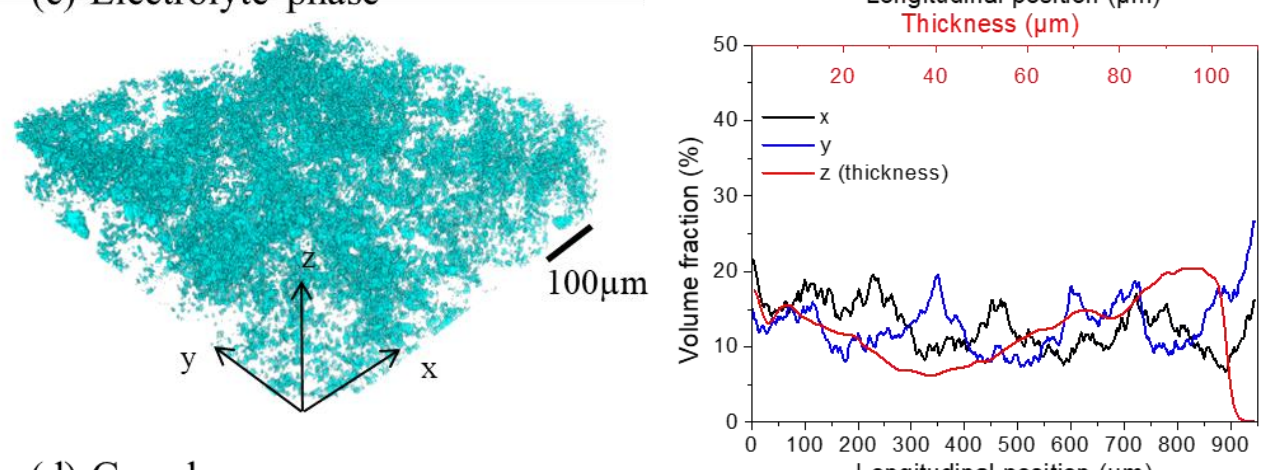

(d) Gas phase
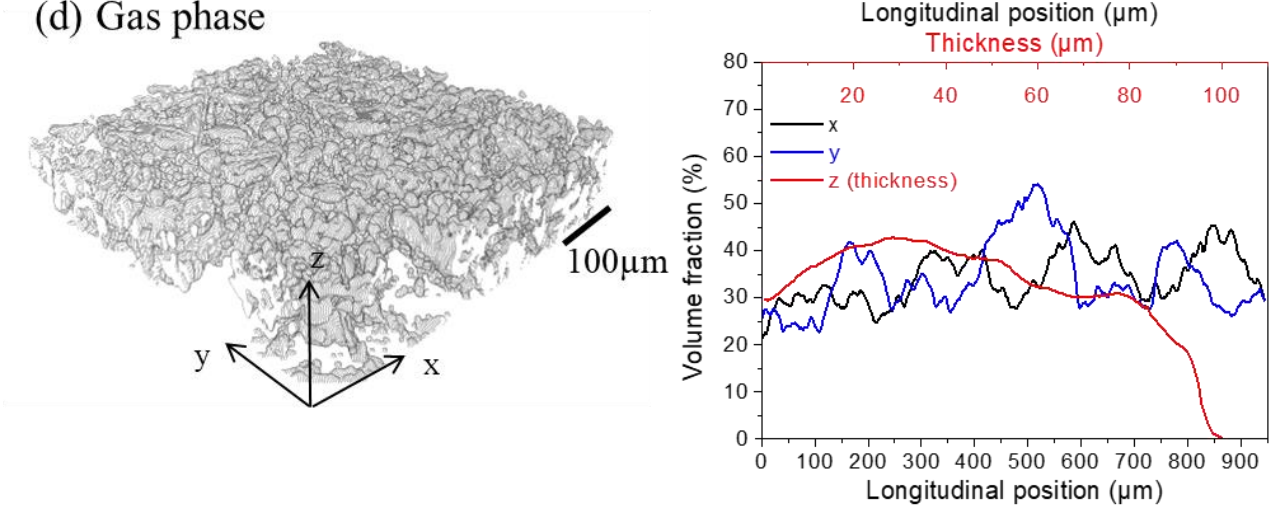

Figure $43 \mathrm{D}$ views and distribution profiles along the $x, y$ and $z$ (thickness) axes of the pristine electrode for the (a) C-rich solid phase, (b) Si phase, (c) electrolyte phase and (d) gas (electrolyte-free pore) phase. 
Fig. 5a shows the evolution of the electrode potential along the $1^{\text {st }}$ and $10^{\text {th }}$ cycles performed during the in situ XRCT/XRD experiments. The numbers 1 to 24 indicated on the discharge/charge curves correspond to the XRCT/XRD acquisition periods, during which the electrode is let to the open circuit potential for about 3 min. A discharge capacity of $1090 \mathrm{mAh}$ $\mathrm{g}^{-1}$ of electrode and a CE of $68 \%$ are obtained at the $1^{\text {st }}$ cycle. At the $10^{\text {th }}$ cycle, the discharge capacity and CE are $580 \mathrm{mAh} \mathrm{g}^{-1}$ and $95 \%$, respectively. These values are lower than those previously obtained using a conventional electrochemical cell (Fig. 3). The larger size of the Si particles (Fig. S3) as well as the incomplete impregnation of the electrode by the electrolyte (Fig. 4) may explain this lower electrochemical performance. Note that the C paper and GnP are also electrochemically active as confirmed in our previous works with a $1^{\text {st }}$ discharge (charge) capacity of 342 (222) $\mathrm{mAh} \mathrm{g}^{-1}$ measured at $180 \mathrm{~mA} \mathrm{~g}^{-1}$ for the $\mathrm{C}$ paper [12] and 1268 (336) $\mathrm{mAh} \mathrm{g}^{-1}$ measured at $40 \mathrm{~mA} \mathrm{~g}^{-1}$ for the $\mathrm{GnP}$ additive [22]. Considering that the electrode contains $47.4 \mathrm{wt} \%$ of $\mathrm{C}$ paper and $5.8 \mathrm{wt} \%$ of $\mathrm{GnP}$ (see Experimental section), this means that about $22 \%$ of the $1^{\text {st }}$ discharge capacity of $1090 \mathrm{mAh} \mathrm{g}^{-1}$ results from the lithiation of the $\mathrm{C}$ paper and GnP. This value of $22 \%$ may be overestimated because of the higher C-rate used in the present study (400 mA g-1 of Si, corresponding to $324 \mathrm{~mA} \mathrm{~g}^{-1}$ of C paper and $2655 \mathrm{~mA} \mathrm{~g}^{-1}$ of $\mathrm{GnP}$ ), which must decrease the lithiation level of the $\mathrm{C}$ paper and $\mathrm{GnP}$ in the Si-based electrode as confirmed below from in-situ XRD analyses. On the basis of the theoretical capacity of $\mathrm{Si}\left(3579 \mathrm{mAh} \mathrm{g}^{-1}\right)$ and its amount in the electrode $(38.5 \mathrm{wt} \%)$, the weight fraction of electrochemical active Si particles can then be estimated in a first approximation at $62 \%$ for the $1^{\text {st }}$ discharge and $45 \%$ for the $1^{\text {st }}$ charge.

Fig. 5b shows XRCT images in the transversal (i.e. orthogonal to the current collector) and lateral (i.e parallel to the current collector) sections of the electrode acquired at different periods of the cycling, namely at the steps 1 (initial state), 9 (end of the $1^{\text {st }}$ discharge), 16 (end of the $1^{\text {st }}$ charge), 17 (beginning of the $10^{\text {th }}$ discharge), 21 (end of the $10^{\text {th }}$ discharge) and 24 
(end of the $10^{\text {th }}$ charge). The red dashed line on the transversal images highlights the interface between the top of the electrode and the bottom of the separator (see Supplemental information on the segmentation procedure for details to determine the position of the separator/electrode interface). The green dashed line corresponds to the $z$ position of the lateral images, which is localized in the middle zone of the electrode thickness. The yellow dashed line in the lateral images corresponds to the $y$ position of the transversal images. The morphological evolution of the electrode is also presented in the movie made from the XRCT images (see Video 1 in Supplemental Information). As clearly evidenced by the displacement of the separator/electrode interface (red dashed line) on the transversal images, the electrode thickness increases during the discharge and decreases during the charge. This expansion/contraction of the electrode is not fully reversible since the dashed red line does not come back to its initial position. By comparing the lateral images, one can see that the electrode porosity (dark areas are electrolytefree pores) varies a little during the electrode expansion/contraction. In contrast, a major decrease of the porosity is observed by comparing the images at the $10^{\text {th }}$ cycle versus $1^{\text {st }}$ cycle. Furthermore, no major cracking is observed upon cycling despite its significant volume variation. This strongly differs from our previous XRCT observations on a Si/C paper electrode with $\mathrm{CB}$ additive, showing the formation of large cracks during the charge (contraction) of the electrode [12]. This is highlighted in Fig. 6, which compares in-situ XRCT images of both electrodes at the end of the $1^{\text {st }}$ cycle. Large cracks are formed in the Si-based electrode with CB additive whereas with GnP additive, the electrode is free of macrocracks. This is also evident by comparing XRCT movies recorded for a similar volume during the $1^{\text {st }}$ cycle of $\mathrm{Si} / \mathrm{C}$ paper electrodes made with $\mathrm{CB}$ or $\mathrm{GnP}$ conductive additive (see Video 2 in Supplemental Information). The fact that no macrocracks are observed upon cycling with the electrode prepared with $\mathrm{GnP}$ in contrast to the electrode prepared with $\mathrm{CB}$ additive tends to confirm that The the mechanical strength of the electrode is increased with GnP additive. This is also 
supported by its lower and more reversible dimensional change (see below). This agrees with its higher capacity retention and lower electrical disconnections observed in Fig. 3c and 3d, respectively. This is also in accordance with our previous study performed on $\mathrm{Si} / \mathrm{Cu}$ electrodes showing a significant positive impact of the GnP additive on the mechanical strength and cyclability of the electrode [22].
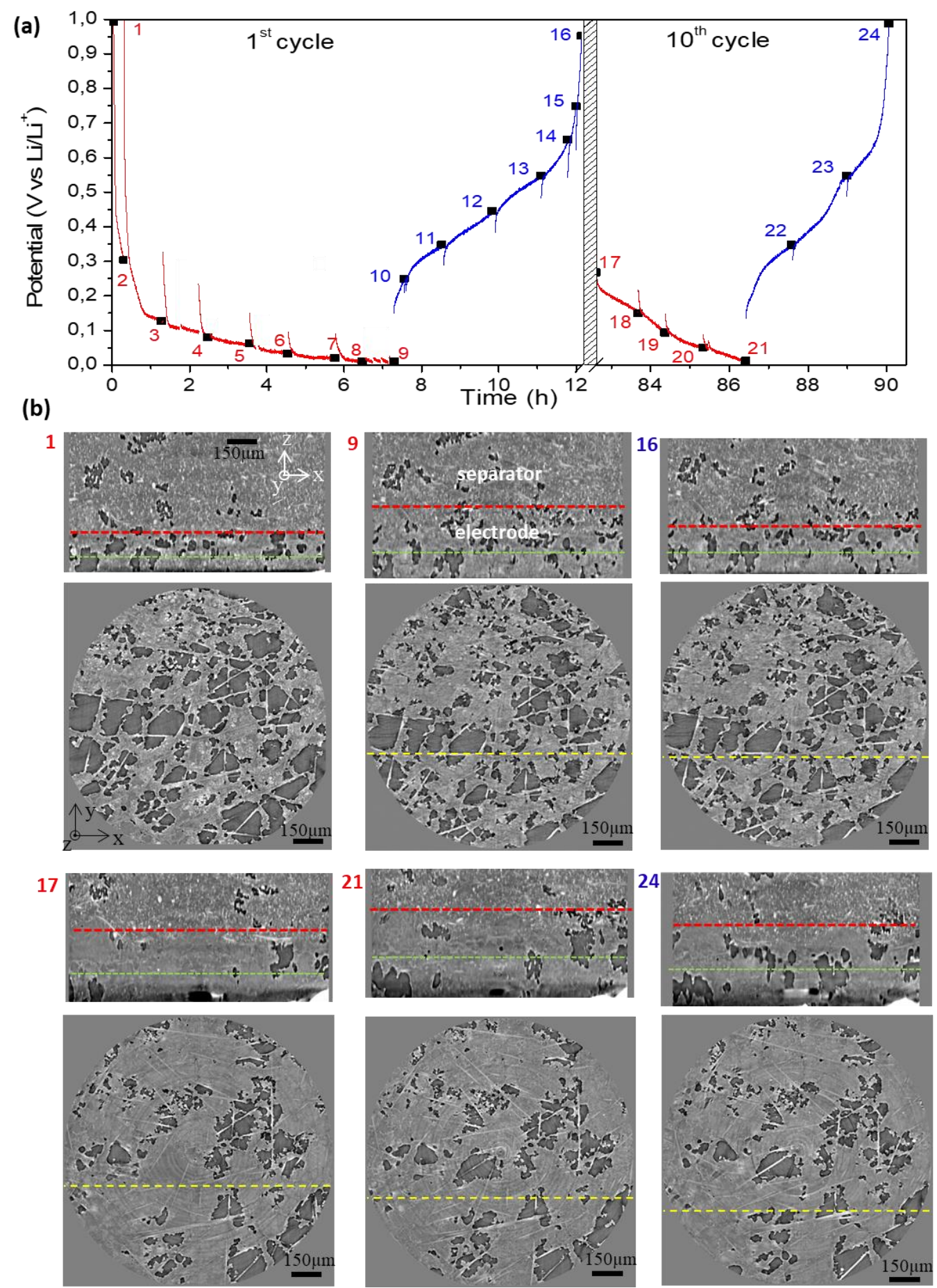
Figure 5 (a) Evolution of the electrode potential during the $1^{\text {st }}$ and $10^{\text {th }}$ cycles; (b) XRCT slice images in the transversal $(\mathrm{x}, \mathrm{z})$ and lateral $(\mathrm{x}, \mathrm{y})$ planes of the electrode for different cycling stages corresponding to the numbers 1,9, 16, 17, 20 and 24 indicated on the potential curve. The red dashed line on the transversal images sets the interface between the top of the electrode and the bottom of the separator. The green dashed line corresponds to the $z$ position of the lateral images. The yellow dashed line in the lateral images corresponds to the $y$ position of the transversal images.
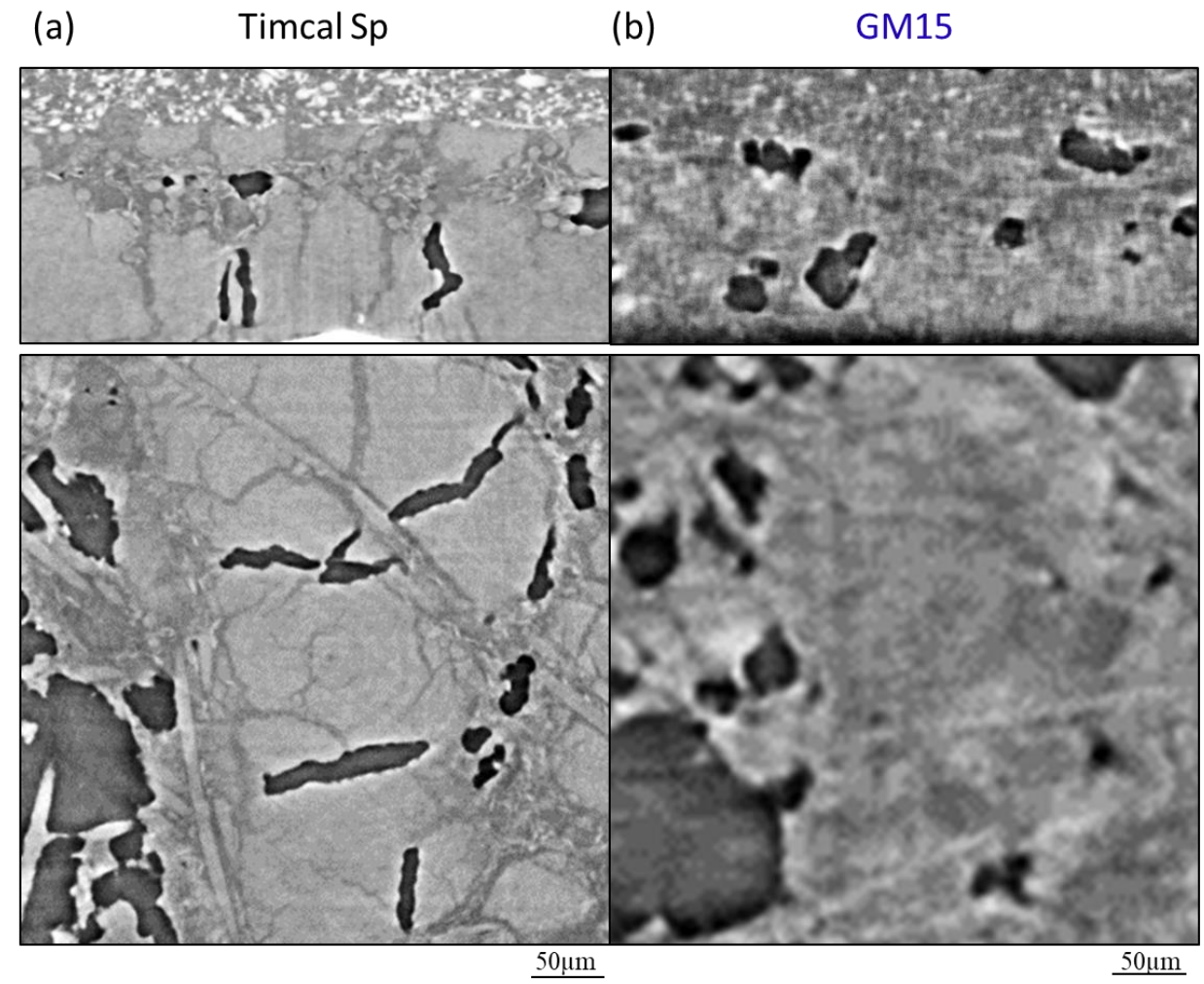

Figure 6 Transversal and lateral XRCT images at the end of the $1^{\text {st }}$ cycle of $\mathrm{Si} / \mathrm{C}$ paper electrodes prepared with (a) $\mathrm{CB}$ and (b) $\mathrm{GnP}$ as conductive additive.

Representative areas of $280 \times 280 \mu \mathrm{m}^{2}$ with discernible Si particles (in white at the pristine state) are chosen across the electrode thickness (at $\mathrm{z}_{\mathrm{o}} \sim 5,50$ and $100 \mu \mathrm{m}$ ) in order to track their lithiation/delithiation along cycling as shown in Fig. 7. As the depth-of-discharge 
(DOD) increases, the brightness of the Si particles decreases since they become less dense due to their lithiation and thus they attenuate less the X-rays. At a DOD of 50\%, only the larger $\mathrm{Si}$ particles are still discernible as they need a deeper discharge to be fully lithiated. The lithiation seems slightly slower at the bottom of the electrode as large Si particles are still visible at $z=5$ $\mu \mathrm{m}$ for $80 \%$ DOD. This might be due to the longer diffusion path (i.e. larger kinetic constraints) for the $\mathrm{Li}$ ions to reach the bottom part of the electrode. During the $1^{\text {st }}$ charge, the Si particles become again progressively visible due to their delithiation, but at the end of the $1^{\text {st }}$ charge, some of them appear darker than at the initial state. Additionally, these ones present an irreversible volume expansion of $\sim 30 \pm 5 \%$ (highlighted by the red dash lines around the large particles before and after the $1^{\text {st }}$ cycle). It may reflect their uncomplete delithiation. No cracks are observed through the large detectable Si particles but note that if present, these would be hard to see due to resolution limitation. Furthermore, it should be considered that their poorly crystallized state at the initial state is likely to limit their fracturing by favoring a more homogeneous deformation of the Si particles during their lithiation $[\mathbf{2 4 , 2 5}$. However, as highlighted by the arrows, the formation of very thin cracks can be noticed between the $\mathrm{Si}$ particles from $80 \%$ SOC, which may be due to their displacement associated with the electrode volume change (see below). After 9-10 cycles, the Si particles are almost no longer discernible, except for a few larger ones. This may be caused by the accumulation of SEI products in the electrode and/or the increasing amount of irreversibly lithiated Si (less dense) particles with cycling, making them less absorbent and then less distinguishable from the other components of the electrode. It is also possible that the size of the Si particles becomes smaller than the present XRCT resolution due to their pulverization upon prolonged cycling [26]. No evident increase of the density or size of the cracks can be observed after 9-10 cycles from the present XRCT analyses. Actually, the particle micro-cracking can be clearly observed by in-situ XRCT 
only when large active material particles are used in the electrode formulation (e.g. 50-100 $\mu \mathrm{m}$ diam. Si particles [7,11], 20 $\mu \mathrm{m}$ diam. SnO particles [27]).

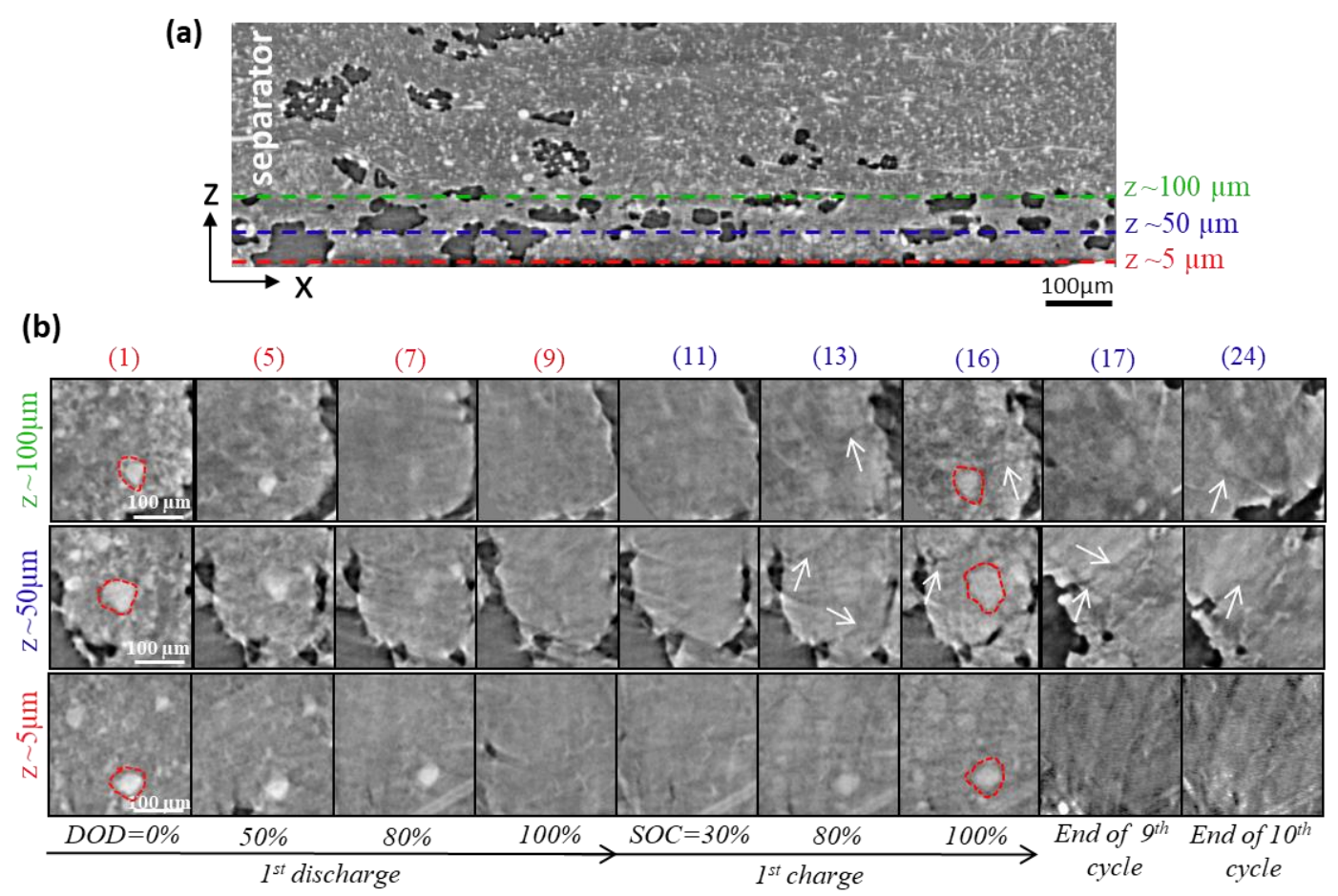

Figure 7 (a) Transversal XRCT image of the electrode at the pristine state. (b) Lateral XRCT images focused on an area of $280 \times 280 \mu \mathrm{m}^{2}$ at $z \sim 5,50$ and $100 \mu \mathrm{m}$ for different stages of cycling. The numbers (1) to (24) correspond to those indicated on the discharge/charge curves in Fig. 5a.

Fig. 8a presents the macroscopic dimensional variation of the electrode along the $x, y$ and $z$ directions during the $1^{\text {st }}$ and $10^{\text {th }}$ cycles. The relative transversal variation $\left(\mathrm{dz} / \mathrm{z}_{0}\right)$ was determined from the displacement of the electrode/separator interface and the relative lateral variations $\left(\mathrm{dx} / \mathrm{x}_{0}\right.$ and $\left.\mathrm{dy} / \mathrm{y}_{0}\right)$ were determined from the displacement of several reference points taken in the electrode at different $z$ values. The relative dimensional variation of the electrode upon cycling is much larger in the transversal (vertical) direction than in the lateral (horizontal) ones. This is expected because the fixed lateral dimensions of the electrochemical cell and the presence of the carbon fibers restrict the in-plane expansion of the electrode, whereas the 
flexibility of the separator implies an easier out-of-plane expansion of the electrode. During the first discharge, the electrode thickness increases progressively but its expansion is more marked from $\sim 4.5 \mathrm{~h}$ (i.e. from a DOD of $\sim 60 \%$ ), with a slope of $11.6 \% \mathrm{~h}^{-1}$ compared to $5.9 \% \mathrm{~h}^{-1}$ from 0 to 4.5 h, as measured in Fig 8a. This may reflect an accentuation of the electrode decohesion due to the rupture of $\mathrm{CMC}$ chains. Its expansion reaches a maximum of $55 \%$ at the end of the $1^{\text {st }}$ discharge. During the subsequent charge, the electrode thickness variation (contraction) is more linear than during its expansion, with a mean slope of $8.5 \% \mathrm{~h}^{-1}$. At the end of the $1^{\text {st }}$ charge, a residual thickness expansion of $11 \%$ is measured, which is indicative of irreversible changes in the electrode architecture (e.g. cracking, rearrangement/disconnection of some $\mathrm{Si}$ particles, SEI formation). However, this irreversible thickness expansion is two times lower than observed on a $\mathrm{Si} / \mathrm{C}$ paper electrode with $\mathrm{CB}$ conductive additive and having a lower $\mathrm{Si}$ loading $\left(1.4 \mathrm{mg} \mathrm{cm}^{-2}\right)$ [12]. This confirms the key role of the $\mathrm{GnP}$ additive to limit the occurrence of permanent mechanical damage in the electrode associated with its volume expansion/contraction. It must be noted that the flexibility and 3D geometry of the $\mathrm{C}$ paper current collector also favor a lower and more reversible expansion/contraction of the electrode

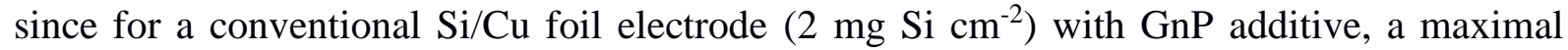
electrode expansion of $400 \%$ and an irreversible expansion of $170 \%$ were measured during the $1^{\text {st }}$ cycle by operando dilatometry [22]. At the $10^{\text {th }}$ cycle, the transversal expansion/contraction of the electrode is lower (35\%) and more reversible (1.5\% of irreversibility) than during the $1^{\text {st }}$ cycle. However, a cumulated irreversible thickness expansion of $35 \%$ is observed after 10 cycles. This may originate from the growth of the SEI layer as well as from the increasing amount of partially delithiated (i.e. electrically disconnected) $\mathrm{SiLi}_{\mathrm{x}}$ particles with cycling.

As complementary information on the dimensional variation of the electrode with cycling, Fig. 8b compares the relative volume variation of the solid phase, pore phase (electrolyte-free pores + electrolyte-filled pores) and whole electrode during the $1^{\text {st }}$ and $10^{\text {th }}$ 
cycles. As the Si phase cannot be differentiated from the C-rich phase $(\mathrm{C}$ paper $+\mathrm{GnP}+\mathrm{CMC}$ + CA) when it is lithiated due to the decrease of its X-ray attenuation coefficient (Fig. $7 \mathbf{b})$, these two phases are included in the labelled "solid phase". This latter also contains the insoluble SEI compounds formed upon cycling [28]. As shown in Fig. 8b, the expansion/contraction of the pore phase during the $1^{\text {st }}$ discharge/charge is lower than for the solid phase, resulting in lower volume variation of the whole electrode. This suggests that the swelling of the Si particles is partially buffered by the electrode pores. This is also highlighted in Fig. 8c, which shows a decrease of the volume fraction of the pore phase (i.e. electrode porosity) during the $1^{\text {st }}$ discharge. This decrease is accentuated at the end of the discharge, which may be due to the compression of the electrode against the separator when the electrode thickness expansion reaches about 50\% (see Fig. 8a). One can also note a major decrease of the electrode porosity from 48 to $21 \%$ between the $1^{\text {st }}$ and $10^{\text {th }}$ cycle. This can be attributed to the continuous growth of the SEI layer with cycling, progressively obstructing the porous network of the electrode. 

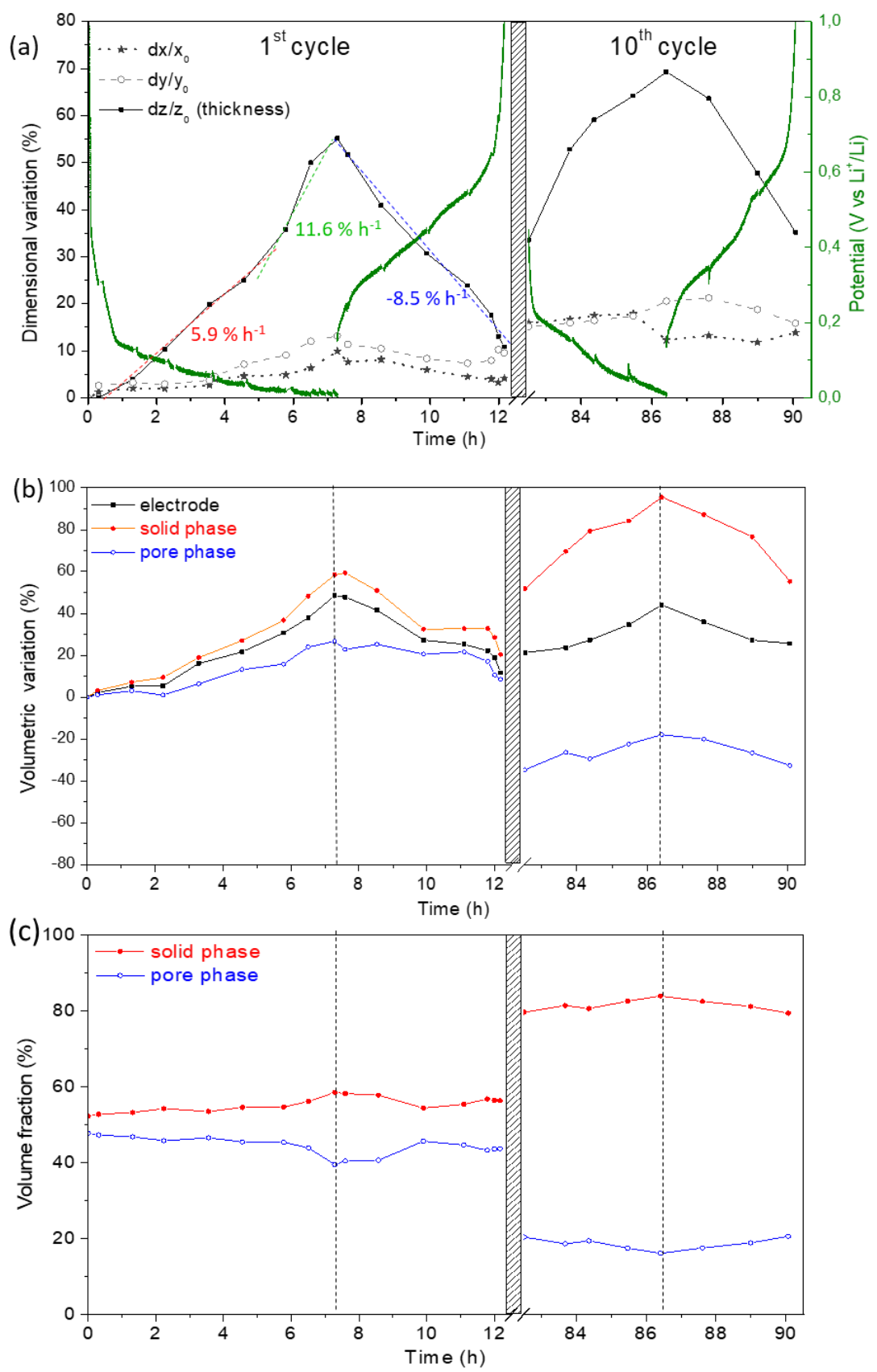

Figure 8 (a) Relative variation of the lateral and transversal dimensions of the electrode, (b) Relative volume variation of the solid phase, pore phase and whole electrode, and (c) Variation of the electrode porosity during the $1^{\text {st }}$ and $10^{\text {th }}$ cycles. 
Fig. 9a-c present the in situ XRD analyses performed during the $1^{\text {st }}$ and $10^{\text {th }}$ cycles. Fig. 9a is a color map representing the evolution of the XRD peak intensities upon cycling. On the left side, the discharge/charge curves are presented with the position of the successive XRD acquisition steps ( 1 to 24 ) for greater clarity. The XRD patterns acquired during the $1^{\text {st }}$ cycle (steps 1-16) and 10 ${ }^{\text {th }}$ cycle (steps 17-24) are shown in Fig. 9b and 9c, respectively. From these XRD patterns, the evolution with cycling of the relative integrated intensity of the $\operatorname{Si}(111)$ peak and the d-spacing of the $\mathrm{C}(002)$ peak are highlighted in Fig. 10a-d.

At the initial state (step 1), three peaks of the crystalline Si phase can be detected at $0.164 \mathrm{~nm}(\operatorname{Si}(331)), 0.192 \mathrm{~nm}(\operatorname{Si}(220))$ and $0.314 \mathrm{~nm}(\operatorname{Si}(111))$, in accordance with JCPDS 00005-0565. Note that a large part of the Si material cannot be easily characterized from the XRD measurements, as the milled Si powder is 63\% amorphous (Fig. 1b). Several peaks attributed to the graphitic phase of the $\mathrm{C}$ paper and $\mathrm{GnP}$ additive are also detected at $0.337 \mathrm{~nm}(\mathrm{C}(002))$, $0.213 \mathrm{~nm}(\mathrm{C}(100))$, and $0.204 \mathrm{~nm}(\mathrm{C}(101))$, in accordance with JCPDS 00-056-0159. Note that the relative intensities of the $\mathrm{C}(100)$ and $\mathrm{C}(101)$ peaks detected around $0.20 \mathrm{~nm}$ are higher than expected from the JCPDS data because the incident intensity of the polychromatic X-ray beam is maximal in this region corresponding to an energy of $\sim 30 \mathrm{keV}$ (see Experimental section). The broad bump at $0.23-28 \mathrm{~nm}$ comes from the PFA polymer of the electrochemical cell as confirmed from XRD analysis of the PFA polymer alone (not shown).

As the DOD increases, one can see in Fig. 9a-b a decrease of the intensity of the c-Si peaks without modification of their position, whereas a broad bump in the $0.20-0.25 \mathrm{~nm}$ region increases in intensity and width, which can be related to the formation of a-Lix $\mathrm{Si}$ from c-Si and a-Si $[29,30]$. As seen in Fig. 10a, the decrease of the intensity of the Si (111) peak becomes significant from a DOD of $\sim 50 \%$. This suggests that the lithiation of a-Si is initiated before that of c-Si, i.e. occurs at higher potential. Similar behavior has been recently observed with crystalline embedded amorphous Si nanoparticles [31]. This can be explained by the lower 
kinetic barrier for breaking $\mathrm{Si}-\mathrm{Si}$ bonds in a-Si than in c-Si, which is the lithiation ratedetermining step for both materials [24]. The Si peaks are still visible at the end of the $1^{\text {st }}$ discharge (a remaining normalized integrated intensity of 0.4 is observed for the Si (111) peak as shown in Fig. 10a). This confirms that some Si particles are not electrochemically accessible. This observation agrees with the value of only $62 \mathrm{wt} \%$ of active Si particles estimated previously from the $1^{\text {st }}$ discharge capacity of the electrode (Fig. 5a), which is mainly attributed to incomplete impregnation of the electrode by the electrolyte.

At the end of the $1^{\text {st }}$ discharge (step 9), two small peaks emerge on the broad bump at about $0.214 \mathrm{~nm}$ and $0.234 \mathrm{~nm}$. They cannot be assigned to c- $\mathrm{Li}_{15} \mathrm{Si}_{4}$ phase, which should display 3 intensive peaks at $0.208 \mathrm{~nm}(431), 0.227 \mathrm{~nm}$ (332) and $0.376 \mathrm{~nm}$ (220), according to JCPDS 01-083-9094. Moreover, they begin to appear from step 3 (DOD 20\% and E 130 mV) whereas it is well known that $\mathrm{c}-\mathrm{Li}_{15} \mathrm{Si}_{4}$ is formed at the end of the discharge (typically below $50 \mathrm{mV}$ ) [29,30]. Actually, these two peaks could be rather related to the lithiation of the $\mathrm{C}$ paper and $\mathrm{GnP}$ additive or to the degradation of the PFA polymer of the cell (see below). The assumption that there is no formation of $\mathrm{c}-\mathrm{Li}_{15} \mathrm{Si}_{4}$ in the present case is also supported by the shape of the $1^{\text {st }}$ charge curve (see Figs. 3a and 5a) and corresponding $d Q / d V$ curve (supplemental Fig. S8), displaying no discernible plateau (narrow peak on dQ/dV curve) at about $0.45 \mathrm{~V}$ characteristic of the $\mathrm{c}-\mathrm{Li}_{15} \mathrm{Si}_{4}$ phase [32]. This can be explained by the amorphous/nanocrystalline structure of the present ball-milled Si powder, favoring its more progressive and homogeneous lithiation likely to prevent the formation of the $c-\mathrm{Li}_{15} \mathrm{Si}_{4}$ phase [33]. It is well known that the formation of $\mathrm{c}-\mathrm{Li}_{15} \mathrm{Si}_{4}$ phase has a detrimental effect on the electrode cyclability [32]. This is also in accordance with in situ TEM experiments on a-Si thin film electrode showing that the final stage of lithiation (from a-Li ${ }_{\sim 2.5} \mathrm{Si}$ ) sets in without a visible interface, resulting in the formation of a- $\mathrm{Li}_{\sim 3.75} \mathrm{Si}$ instead of $\mathrm{c}-\mathrm{Li}_{15} \mathrm{Si}_{4}$ as final product [34]. No c- $\mathrm{Li}_{15} \mathrm{Si}_{4}$ phase was also observed by in situ synchrotron XRD with Si nanoparticles in contrast 
to micrometric Si particles discharged under the same conditions [35]. Despite its micrometric size $\left(\mathrm{D}_{50}=6 \mu \mathrm{m}\right.$ in as-milled state, Fig. S3), and thanks to its initial nanocrystalline/amorphous structure, the present ball-milled powder presents thus the benefits of nanosized Si powder but without the drawbacks as it is easy to handle and it can be produced at low cost and large scale [33]. 
(a)

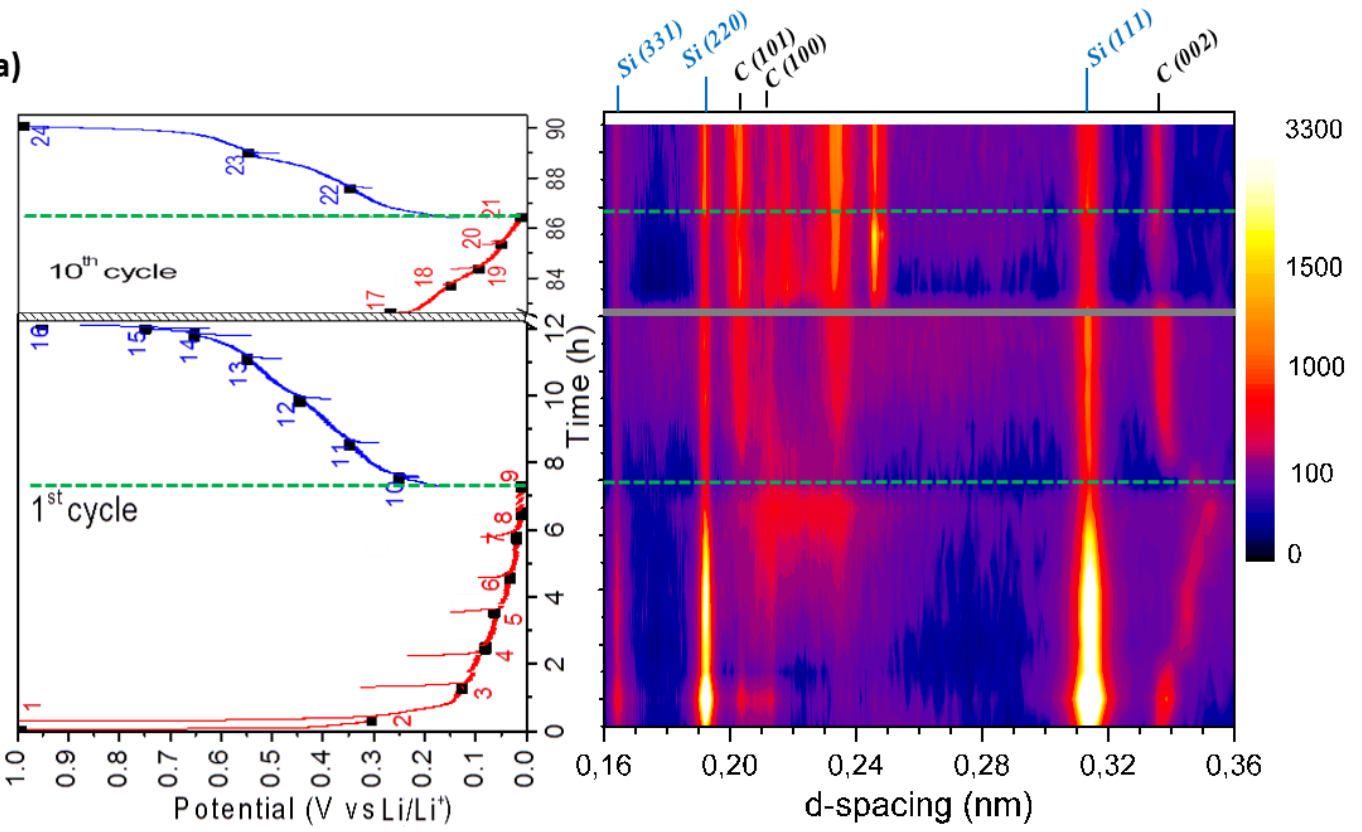

(b)

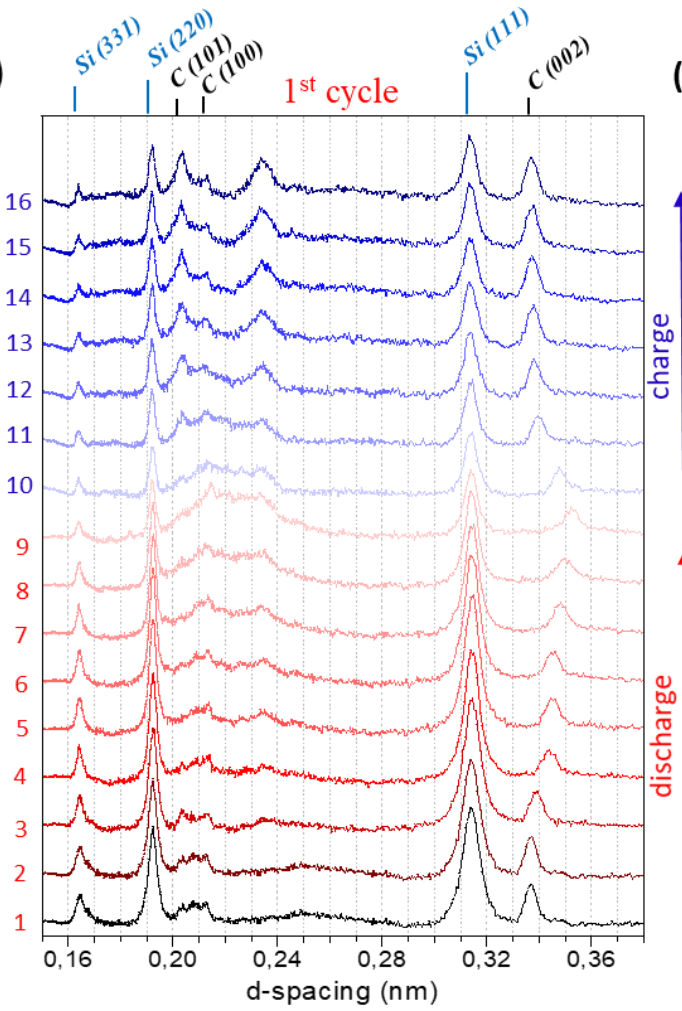

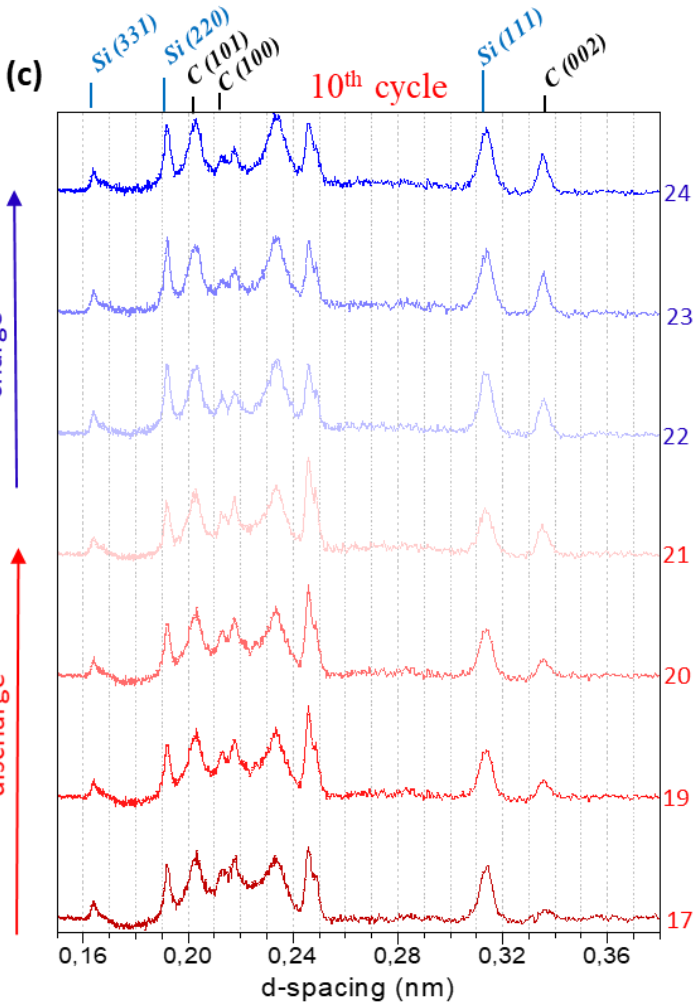

Figure 9 (a) Color map displaying the evolution of the XRD peak intensities upon cycling. On the left side, the discharge/charge curves are presented with the position of the successive XRD acquisition steps 1 to 24 , (b, c) XRD patterns acquired during the $1^{\text {st }}$ cycle (steps $\left.1-16\right)$ and $10^{\text {th }}$ cycle (steps 17-24). 
Regarding the $\mathrm{C}$ peaks of the graphitic phase, they are broadened and shifted towards higher d-spacing values from step 3 (DOD 20\%) as highlighted in Fig. 10b for the C(002) peak. This confirms the lithiation of the $\mathrm{C}$ paper and $\mathrm{GnP}$ additive during the electrode discharge as this lithiation is an insertion reaction inducing an increase in the d-spacing of the carbon lattice. The (002) d-spacing reaches a maximum value of $0.353 \mathrm{~nm}$ at the end of the $1^{\text {st }}$ discharge, corresponding to $x=0.5$ in $\mathrm{Li}_{\mathrm{x}} \mathrm{C}_{6}\left[\mathbf{3 6 , 3 7 ]}\right.$. This means that the final stage- $1 \mathrm{LiC}_{6}$ reaction does not occur here, probably because of kinetic limitation due the present high C-rate for the graphite phase as previously discussed from Fig. 5a. As shown in Fig. 10b, the C(002) peak goes back to its initial position $(\mathrm{d}=0.337 \mathrm{~nm})$ during the first charge steps $(10-12)$, indicating that the delithiation of the $\mathrm{Li}_{\mathrm{x}} \mathrm{C}_{6}$ phase occurs nearly completely in the first stage of the charge.

No notable change is visible for the intensity of Si peaks during the $1^{\text {st }}$ charge (Fig. 10a), which is expected since these remaining peaks are associated with still inactive Si particles. On the other hand, a decrease of the intensity of the broad bump at $0.20-0.25 \mathrm{~nm}$ is observed in Fig. 9b, in accordance with the delithiation of a-Lix $\mathrm{Si}$ in a-Si $[\mathbf{2 9 , 3 0 ]}$. The peaks at 0.204 and $0.213 \mathrm{~nm}$ correspond to $\mathrm{C}(101)$ and $\mathrm{C}(100)$ of the graphite phase as previously argued. However, their intensity is higher than at the initial state, especially for the $\mathrm{C}(101)$ peak. This higher intensity may reflect some irreversible structural rearrangement of the $\mathrm{C}$ paper and/or GnP additive induced by their lithiation and/or by their deformation and high strain generated by the volume change of the surrounding Si particles. This microstructural change of the carbon phase may also be at the origin of the broad peak at $0.234 \mathrm{~nm}$, which becomes more visible as the SOC increases and which was already detected from step 3 in discharge.

At the $10^{\text {th }}$ cycle, the XRD patterns show numerous and intensive peaks in the $0.19-0.25$ $\mathrm{nm}$ region (Fig. 9c). New peaks appear at $0.218,0.246$ and $0.249 \mathrm{~nm}$. They may correspond to crystalline SEI products accumulated with cycling. However, these peaks do not correspond to 
usual SEI products such as LiF (main peaks at 0.201 and $0.232 \mathrm{~nm}$ according to JCPDS 00004-0857) or $\mathrm{Li}_{2} \mathrm{CO}_{3}$ (main peaks at 0.281 and $0.292 \mathrm{~nm}$ according to JCPDS 00-022-1141). The peaks of the c-Si phase attributable to inactive Si particles are still visible and do not change significantly in intensity upon discharge and charge (Fig. 10c). The electrode capacity is assured by the electrochemically accessible a-Si particles, which are not detectable by XRD. The $\mathrm{C}(002)$ peak of the graphite phase is also visible but its position $(\mathrm{d}=0.336 \mathrm{~nm})$ does not vary with cycling (Fig. 10d). This is unexpected and difficult to explain. Moreover, this is in contradiction with the $\mathrm{dQ} / \mathrm{dV}$ curve at the $10^{\text {th }}$ cycle, displaying a peak at $\sim 0.18 \mathrm{~V}$ characteristic of the delithiation of the graphitic phase (see supplementary Fig. S8), and thus suggesting that the graphitic phase is still active. One can also note that the intensity of the $C(002)$ peak largely increases during the discharge whereas the intensities of the $C(100)$ and $C(101)$ peaks seem to be unchanged. The origin of this behavior is presently unclear.
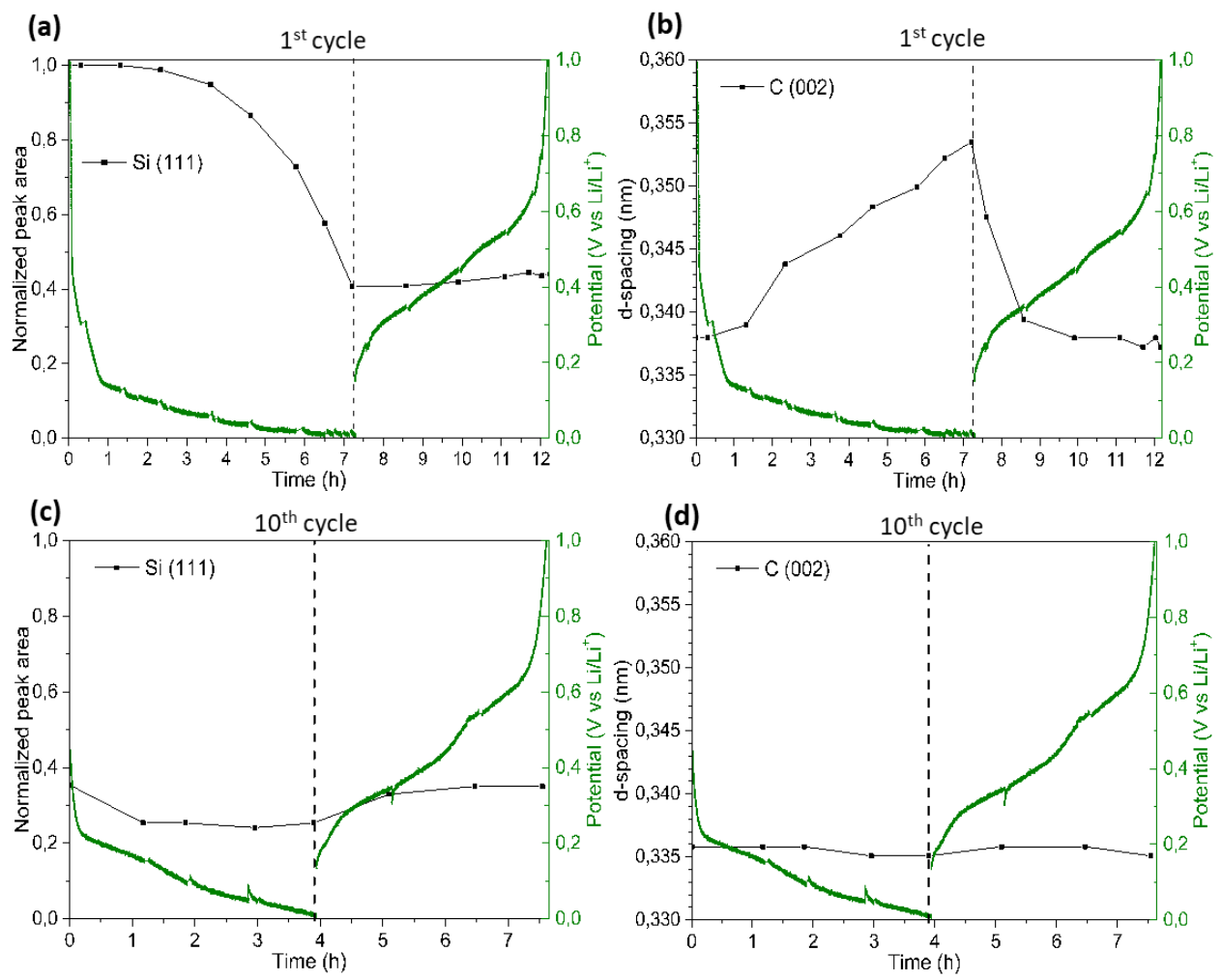

Figure 10 Evolution of the relative integrated intensity of the $\operatorname{Si}(111)$ peak $(a, c)$ and of the dspacing of the $C(002)$ peak $(b, d)$ during the $1^{\text {st }}$ cycle $(a, b)$ and $10^{\text {th }}$ cycle $(c, d)$. 


\section{Conclusion}

This study has shown that relevant qualitative and quantitative information on the structural variation of Si-based anodes induced by cycling can be obtained from in situ combined synchrotron XRCT/XRD analyses performed at different stages of the $1^{\text {st }}$ and $10^{\text {th }}$ cycles. It has been demonstrated that the use of graphene nanoplatelets as conductive additive instead of usual carbon black particles prevent the macroscopic cracking at the electrode upon cycling. In addition, the flexibility and 3D geometry of the $\mathrm{C}$ paper current collector favor a lower and more reversible expansion/contraction of the electrode compared to a conventional $\mathrm{Si} / \mathrm{Cu}$ foil electrode. From the XRD data, it was established that the lithiation of amorphous Si is initiated before that of crystalline Si. Moreover, no formation of c- $\mathrm{Li}_{15} \mathrm{Si}_{4}$ was observed. However, the capacity fade with cycling remains significant. It may originate from the displacement and/or microcracking of the $\mathrm{Si}$ particles due to their volume change, inducing some electrical disconnections and irreversibility of the lithiation reaction. However, this degradation process occurring at the particle scale cannot be clearly identified from the present in-situ XRCT measurements due to spatial resolution limitation. The capacity fade may also result from the accumulation of SEI products with cycling, progressively obstructing the porous network of the electrode, as supported by a significant decrease of the electrode porosity from 48 to $21 \%$ between the $1^{\text {st }}$ and $10^{\text {th }}$ cycle.

\section{Acknowledgments}

The authors thank the Natural Sciences and Engineering Research Council (NSERC) of Canada (Grant No. RGPIN-2016-04524) for supporting this work. We thank also the Soleil synchrotron's reviewing committee for the shifts allocation. A special thought for the precious help of Q. Lemarié, G. Meyruey and J. Adrien during the in-situ XRCT/XRD measurements. 


\section{References}

[1] J. Li, Z. Du, R.E. Ruther, S.J. An, L.A. David, K. Hays, M. Wood, N.D. Phillip, Y. Sheng, C. Mao, S. Kalnaus, C. Daniel, D.L. Wood. Toward Low-Cost, High-Energy Density, and High-Power Density Lithium-Ion Batteries, JOM 69 (2017) 1484-1496.

[2] D. Howell, B. Cunningham, T. Duong, P. Faguy, Overview of the DOE VTO Advanced Battery R\&D Program. US Department of Energy, Washington DC, 2016.

[3] Y. Jin, B. Zhu, Z. Lu, N. Liu, J. Zhu. Challenges and recent progress in the development of Si anodes for lithium-ion battery. Adv. Energy Mater. (2017) 1700715.

[4] M.N. Obrovac, Si-alloy negative electrodes for Li-ion batteries, Curr. Opin. Electrochem. $9(2018) 8-17$.

[5] E. Maire, P.J. Withers. Quantitative X-ray tomography. Inter. Mat. Rev. 59 (2014) 1-43.

[6] F. Tariq, V. Yufit, D. S. Eastwood, Y. Merla, M. Biton, B. Wu, Z. Chen, K. Freedman, G. Ofeer, E. Peled, P. D. Lee, D. Golodnitsky, and N. Brandon, In-Operando X-ray Tomography Study of Lithiation Induced Delamination of Si Based Anodes for LithiumIon Batteries, ECS Electrochem. Lett. 3 (2014) A76-A78.

[7] J. Gonzalez, K. Sun, M. Huang, J. Lambros, S. Dillon, I. Chasiotis, Three dimensional studies of particle failure in silicon based composite electrodes for lithium ion batteries, J. Power Sources 269 (2014) 334-343.

[8] F. Sun, H. Markötter, I. Manke, A. Hilger, N. Karddjilov, J. Banhart, Three-Dimensional Visualization of Gas Evolution and Channel Formation inside a Lithium-Ion Battery, ACS Appl. Mater. Interfaces 8 (2016) 7156-7164.

[9] F. Sun, H. Markötter, K. Dong, I. Manke, A. Hilger, N. Karddjilov, J. Banhart, Investigation of failure mechanisms in silicon based half cells during the first cycle by micro X-ray tomography and radiography, J. Power Sources 321 (2016) 174-184. 
[10] J.M. Paz-Garcia, O.O. Taiwo, E. Tudisco, D.P. Finegan, P.R. Shearing, D.J.L Brett, S.A. Hall, 4D analysis of the microstructural evolution of Si-based electrodes during lithiation: Time-lapse X-ray imaging and digital volume correlation, J. Power Sources 320 (2016) 196-203.

[11] O. O. Taiwo, J.M. Paz-García, S. A. Hall, T. M.M. Heenan, D. P. Finegan, R. Mokso, P. Villanueva-Perez, A. Patera, D. J.L. Brett, PéR. Shearing. Microstructural degradation of silicon electrodes during lithiation observed via operando X-ray tomographic imaging. J. Power Sources 342 (2017) 904-912.

[12] V. Vanpeene, A. Etiemble, A. Bonnin, E. Maire, L. Roué. In-situ X-ray tomographic study of the morphological changes of a Si/C paper anode for Li-ion batteries. J. Power Sources 350 (2017) 18-27.

[13] P. Pietsch, M. Hess, W. Ludwig, J. Eller, V. Wood, Combining operando synchrotron Xray tomographic microscopy and scanning X-ray diffraction to study lithium ion batteries, Sci. Rep. 6 (2016) 27994.

[14] A.T. Voutsas, M.K. Hatalis, J. Boyce, A. Chiang. Raman spectroscopy of amorphous and microcrystalline silicon films deposited by low-pressure chemical vapor deposition. J. Appl. Phys. 78 (1995) 6999-7006.

[15] H. P. Klug, L. E. Alexander. X-ray diffraction procedures for polycrystalline and amorphous materials, John Wiley \& Sons, New York, 1974.

[16] J.Y. Huang, H. Yasuda, H. Mori. Deformation-induced amorphization in ball-milled silicon. Phil. Mag. Lett. 79 (1999) 305-314.

[17] D. Mazouzi, B. Lestriez, L. Roué, D. Guyomard, Silicon composite electrode with high capacity and long cycle life, Electrochem. Solid-State Lett. 12 (2009) A215-A218. 
[18] A. Tranchot, H. Idrissi, P. X. Thivel, L. Roué, Impact of the slurry $\mathrm{pH}$ on the expansion/contraction behavior of silicon/carbon/carboxymethylcellulose electrodes for Li-ion batteries, J. Electrochem. Soc. 163 (2016) A1020-A1026.

[19] A. King, N.Guignot, P. Zerbino, E. Boulard, K. Desjardins, M. Bordessoule, N. Leclerq, S. Le, G. Renaud, M. Cerato, M. Bornert, N. Lenoir, S. Delzon, J.-P. Perrillat, Y. Legodec, J.-P. Itié, Tomography and imaging at the PSICHE beam line of the SOLEIL synchrotron, Rev. Sci. Instrum. 87 (2016) 093704.

[20] A. Mirone, E. Brun, E. Gouillart, P. Tafforeau, J. Kieffer, The PyHST2 hybrid distributed code for high speed tomographic reconstruction with iterative reconstruction and a priori knowledge capabilities, Nucl. Instrum. Methods Phys. Res. B 324 (2014) 41-48.

[21] J. Schindelin, I. Arganda-Carreras, E. Frise, V. Kaynig, M. Longair, T. Pietzsch, S. Preibisch, C. Rueden, S. Saalfeld, B. Schmid, J.Y. Tinevez, D. J. White, V. Hartenstein, K. Eliceiri, P. Tomancak, A. Cardona, Fiji: an open-source platform for biological-image analysis. Nat. Methods 9 (2012) 676-682.

[22] Z. Karkar, D. Mazouzi, C. Reale Hernandez, D. Guyomard, L. Roué, B. Lestriez. Threshold-like dependence of silicon-based electrode performance on active mass loading and nature of carbon conductive additive. Electrochim. Acta 215 (2016) 276-288.

[23] C. Reale Hernandez, A. Etiemble, D. Mazouzi, Z. Karkar, E. Maire, D. Guyomard, B. Lestriez, L. Roué. A Facile and Very Effective Method to Enhance the Mechanical Strength and the Cyclability of Si-Based Electrodes for Li-Ion Batteries. Adv. Energy Mater. 8 (2018) 1701787.

[24] M.T. McDowell, S. W. Lee, J. T. Harris, B. A. Korgel, C. Wang, W. D. Nix, Y. Cui. In Situ TEM of Two-Phase Lithiation of Amorphous Silicon Nanospheres. Nano Lett. 13 (2013) 758-764. 
[25] X. Wang, F. Fan, J. Wang, H. Wang, S. Tao, A. Yang, Y. Liu, H. B. Chew, S.X. Mao, T. Zhu, S. Xia. High damage tolerance of electrochemically lithiated silicon. Nature Comm. $6(2015) 8417$.

[26] M. Ebner, F. Marone, M. Stampanoni, V. Wood. Visualization and Quantification of Electrochemical and Mechanical Degradation in Li Ion Batteries. Science 342 (2013) 716-720.

[27] C. Zhao, T. Wada, V. De Andrade, D. Gursoy, H. Kato, Y-C. K. Chen-Wiegart. Imaging of 3D Morphological Evolution of Nanoporous Silicon Anode in Lithium Ion Battery by X-Ray Nano-Tomography. Nano Energy 52 (2018) 381-390.

[28] V. Etacheri, O. Haik, Y. Goffer, G.A. Roberts, I.C. Stefan, R. Fasching, D. Aurbach. Effect of Fluoroethylene Carbonate (FEC) on the Performance and Surface Chemistry of Si-Nanowire Li-Ion Battery Anodes. Langmuir 28 (2012) 965-976.

[29] T. D. Hatchard, J. R. Dahn. In Situ XRD and Electrochemical Study of the Reaction of Lithium with Amorphous Silicon. J. Electrochem. Soc. 151 (2004) A838-A842.

[30] J. Li, J. R. Dahn. An In Situ X-Ray Diffraction Study of the Reaction of Li with Crystalline Si. J. Electrochem. Soc. 154 (2007) A156-A161.

[31] Y. Zhou, H. Guo, G. Yan, Z. Wang, X. Li, Z. Yang, A. Zheng, J. Wang. Fluidized bed reaction towards crystalline embedded amorphous $\mathrm{Si}$ anode with much enhanced cycling stability. Chem. Commun. 54(2018) 3755-3758.

[32] D.S.M. Iaboni, M.N. Obrovac. $\mathrm{Li}_{15} \mathrm{Si}_{4}$ formation in silicon thin film negative electrodes. J. Electrochem. Soc. 163 (2016) A255-A261.

[33] M. Gauthier, D. Mazouzi, D. Reyter, B. Lestriez, P. Moreau, D. Guyomard, L. Roué, L. Roue, A low-cost and high performance ball-milled Si-based negative electrode for highenergy Li-ion batteries, Energy Environ. Sci. 6 (2013) 2145-2155 
[34] J.W. Wang, Y. He, F. Fan, X. H. Liu, S. Xia, Y. Liu, C. T. Harris, H. Li, J.Y. Huang, S.X. Mao, T. Zhu. Two-Phase Electrochemical Lithiation in Amorphous Silicon. Nano Lett. 13 (2013) 709-715.

[35] F. Wang, L. Wu, B. Key, X-Q. Yang, C.P. Grey, Yi. Zhu, J. Graetz, Electrochemical Reaction of Lithium with Nanostructured Silicon Anodes: A Study by In-Situ Synchrotron X-Ray Diffraction and Electron Energy-Loss Spectroscopy, Adv. Energy Mater. 3 (2013) 1324-1331.

[36] J. R. Dahn, R. Fong, M.J. Spoon. Suppression of staging in lithium-intercalated carbon by disorder in the host. Phys. Rev. B 42 (1990) 6424-6432.

[37] J. R. Dahn. Phase diagram of Li $_{x} C_{6}$. Phys. Rev. B 44 (1991) 9170-9177. 


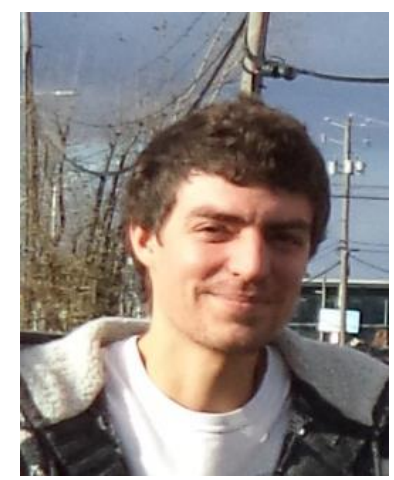

Victor Vanpeene is currently finalizing his Ph.D. in energy and materials science conducted jointly at the Institut National de la Recherche Scientifique (INRS, Canada) and the MateIS laboratory (INSA-Lyon, France). Previously he obtained his engineer degree from INP Phelma (Grenoble, France). His current research interests focus on developing Si-based anodes for Liion batteries and on their characterization by in-situ X-ray tomography.

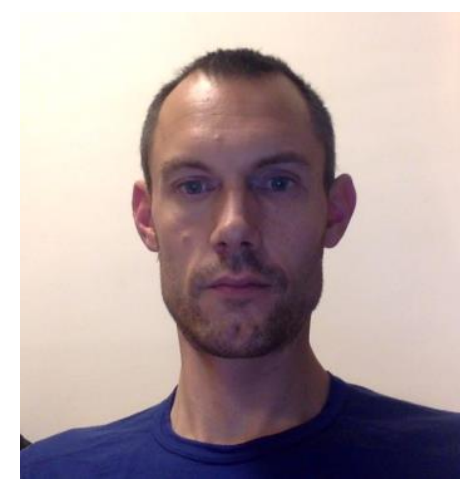

Andrew King is beamline scientist at the PSICHE beamline of Synchrotron SOLEIL, where he is responsible for tomography and imaging for a wide range of user applications. His own research is based on combining imaging and diffraction techniques for materials science. He was formerly based at the ESRF, Grenoble, where he was involved in the development and application of diffraction contrast tomography (DCT). 


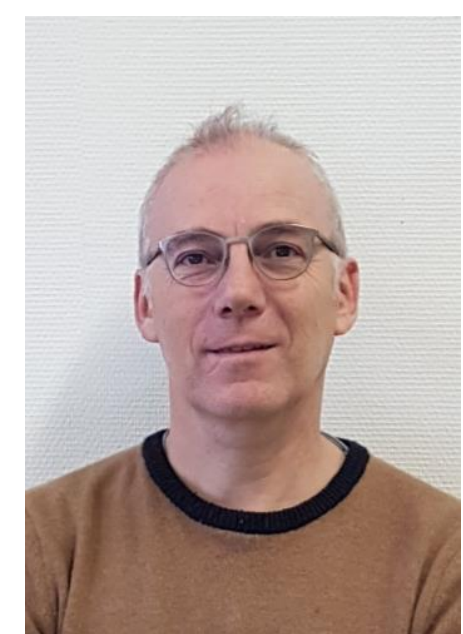

Eric Maire is CNRS research director at the MateIS laboratory INSA de Lyon Villeurbanne France since 1997. His research is focused on the study of microstructure and deformation modes of metals and highly porous materials. He pioneered in situ tensile tests in X-ray computed tomography and diffraction using synchrotron facilities to image and characterize materials non-destructively in 3D.

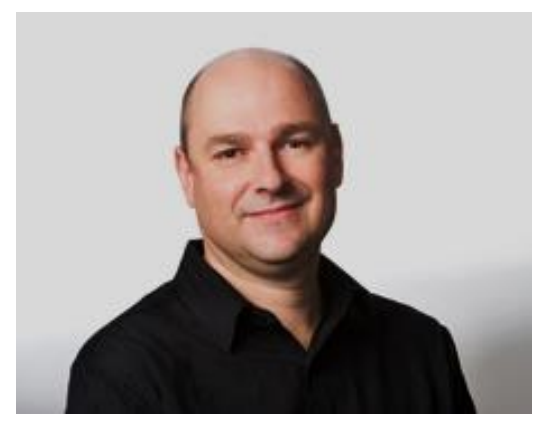

Lionel Roué is a professor at the Institut National de la Recherche Scientifique - Centre Énergie, Matériaux, Télécommunications (INRS-EMT, Canada) since 1998. His research group is focused on the study of electrode materials (especially nanostructured/metastable materials elaborated by high-energy ball milling) for various applications, including Li batteries and $\mathrm{Al}$ production. He has also a strong interest in the development of in-situ characterization tools for battery materials such as tomography, dilatometry and acoustic emission. 